University of Louisville

ThinkIR: The University of Louisville's Institutional Repository

$12-2018$

\title{
Assessing the affects of treatment services, financial assistance, race/ethnicity, and income on the criminal justice outcomes of women on probation.
}

Jordan Wilfong

University of Louisville

Follow this and additional works at: https://ir.library.louisville.edu/etd

Part of the Social and Behavioral Sciences Commons

\section{Recommended Citation}

Wilfong, Jordan, "Assessing the affects of treatment services, financial assistance, race/ethnicity, and income on the criminal justice outcomes of women on probation." (2018). Electronic Theses and Dissertations. Paper 3130.

https://doi.org/10.18297/etd/3130

This Doctoral Dissertation is brought to you for free and open access by ThinkIR: The University of Louisville's Institutional Repository. It has been accepted for inclusion in Electronic Theses and Dissertations by an authorized administrator of ThinkIR: The University of Louisville's Institutional Repository. This title appears here courtesy of the author, who has retained all other copyrights. For more information, please contact thinkir@louisville.edu. 


\title{
ASSESSING THE AFFECTS OF TREATMENT SERVICES, FINANCIAL ASSISTANCE, RACE/ETHNICITY, AND INCOME ON THE CRIMINAL JUSTICE OUTCOMES OF WOMEN ON PROBATION
}

\author{
By \\ Jordan Wilfong \\ B.S., James Madison University, 2008 \\ M.S.W., Widener University, 2011
}

A Dissertation submitted to the Faculty of the Raymond A. Kent School of Social Work in Fulfillment of the Requirements for the Degree of

Doctor of Philosophy in Social Work

Social Work

University of Louisville

Louisville, KY

December 2018 
Copyright 2018 by Jordan Wilfong

All rights reserved 

ASSESSING THE AFFECTS OF TREATMENT SERVICES, FINANCIAL ASSISTANCE, RACE/ETHNICITY, AND INCOME ON THE CRIMINAL JUSTICE OUTCOMES OF WOMEN ON PROBATION

\author{
By \\ Jordan Wilfong \\ B.S., James Madison University, 2008 \\ M.S.W., Widener University, 2011
}

A Dissertation Approved on

August 9, 2018

By the following dissertation committee

Dr. Seana Golder

Dr. Maurice Gattis

Dr. Martin Hall

Dr. Lesley Harris

Dr. Melanie Otis 


\section{DEDICATION}

This dissertation is dedicated to:

1. My wife, my siblings, and my parents.

2. My chair, Dr. Seana Golder, and committee members Drs. Maurice Gattis, Martin Hall, Lesley Harris, and Melanie Otis

3. Kent School of Social Work faculty and staff members Drs. Bibhuti Sar, Dr. Crystal-Collins Camargo, Lynetta Mathis, and Norma Kyriss. 


\begin{abstract}
ASSESSING THE AFFECTS OF TREATMENT SERVICES, FINANCIAL ASSISTANCE, RACE/ETHNICITY, AND INCOME ON THE CRIMINAL JUSTICE OUTCOMES OF WOMEN ON PROBATION
\end{abstract}

\author{
Jordan Wilfong
}

August 9, 2018

The aim of this study is to examine the affect that treatment services have on the criminal justice outcomes of women on probation. The research to date on the treatment services provided to the criminal justice population has tended to focus on prisoners rather than probationers, with even fewer studies that include samples of women on probation. This study will investigate the impact on criminal justice outcomes of services intended to treat issues identified to increase recidivism among female probationers, such as substance use disorders, illicit drug use, mental health issues, and poverty. An additional assessment is conducted to determine the affect of race/ethnicity on the recidivism outcomes of the participants given the history of racial discrimination within the U.S. criminal justice system.

The sample for this study included 247 women on probation that participated in three waves of data collection over a four-year period. Logistic regression models, chi-square tests, and $t$ tests were performed to determine the relationship that treatment services for substance use, mental health, employment services, and financial assistance had on the recidivism outcomes of the participants over the course of the study. Information on the race/ethnicity and income of the participants 
were also investigated in the logistic regression models, chi-square tests, and $t$ tests to assess their affect on recidivism outcomes.

The findings of the logistic regression indicated that reception of more social security or disability throughout the study reduced the likelihood of recidivism, while receiving more substance use and mental health treatment services during the study increased occurrences of recidivism. Additionally, the findings from the chi-square and $t$ test identified that participants recidivated significantly more often if they received more substance use and mental health treatment during the study in addition to using more types of illicit drugs in the past 12 months at the baseline interview, and were less likely to experience recidivism if they accessed more social security or disability throughout the study. The implications for policies and practices at U.S. probation departments are also discussed, which include expansion of affordable evidence-based practices for substance use and mental health, providing financial assistance to address the high instances of poverty among the population, elimination of the financial barriers placed on offenders by the criminal justice system, and eradication of policing practices that target African Americans. 


\section{TABLE OF CONTENTS}

\section{PAGE}

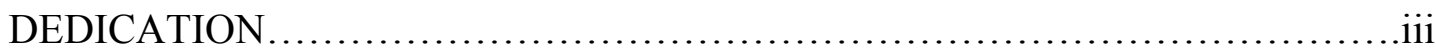

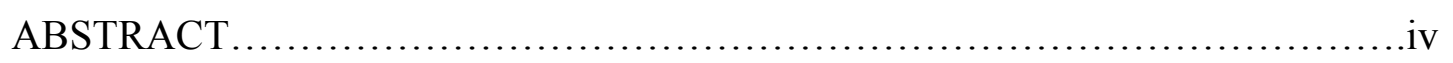

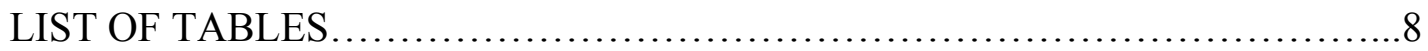

CHAPTER I: INTRODUCTION.............................................

Statement of the Problem..........................................................

Importance of Feminist Criminology ........................................

The Paradox of Probation.................................................... 6

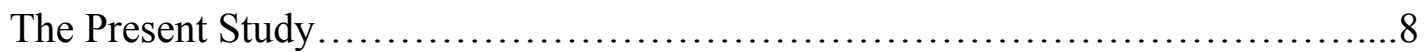

CHAPTER II: LITERATURE REVIEW ................................... 10

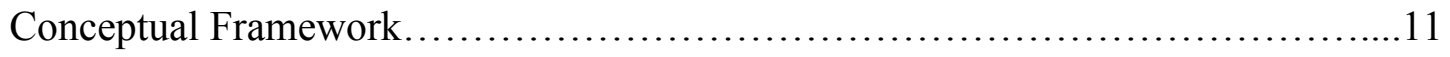

The Pathways Perspective...............................................12

Social and Human Capital Theories.....................................14

Applying Race/Ethnicity to Conceptual Framework.........................16

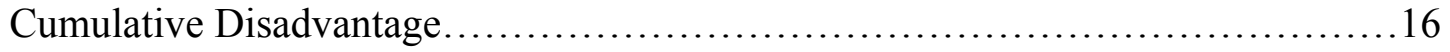

Occurrences of Victimization.......................................... 17

Health Issues Associated with Victimization...............................18

Victimization and Female Crime..........................................19

Occurrences of Substance Use........................................19 
Health Issues Associated with Substance $\quad$............................20

Substance Use and Female Crime.....................................20

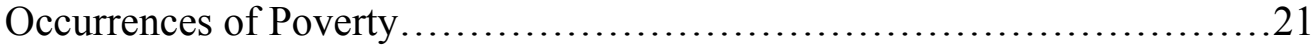

Poverty and Female Crime.........................................23

Racial Disproportionality Among Probationers...............................24

Poverty and Race Among African American Women.......................26

Probation Recidivism Among Women.......................................27

Legal Issues Linking Probation and Incarceration.......................29

Factors Influencing Probation Recidivism Among Women..................31

Racial Disparities in Probation Recidivism.............................33

Treatment Services During Probation........................................ 34

Cumulative Disadvantage and Treatment Services........................34

Treatment Services for Female Probationers............................35

Access to Treatment Services............................................ 37

Race/Ethnicity and Treatment Access.................................38

Addressing Gaps in the Literature............................................ 38

CHAPTER III: METHODOLOGY .......................................40

Overview of the Study................................................... 40

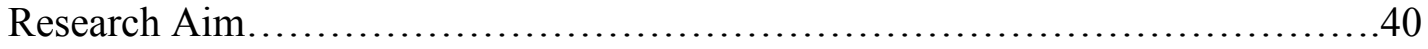

Sampling and Recruitment..............................................41 
WHRS Data Collection................................................42

Independent Variables...................................................43

Control/Descriptive Variables........................................47

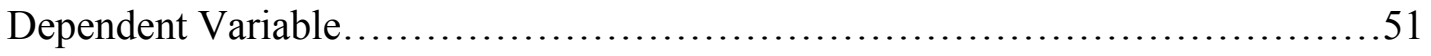

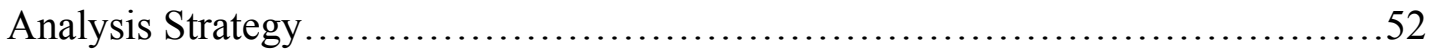

CHAPTER IV: RESULTS ...........................................54

Missing Data Analysis....................................................54

Descriptive Findings................................................64

Sociodemographic Variables......................................64

Drug and Alcohol Use..........................................6 64

Victimization.................................................65

Bivariate Results.................................................... 70

Logistic Regression Results.......................................... 73

Substance Use Treatment, Race/Ethnicity, and Income Model.............73

Mental Health Treatment, Race/Ethnicity, and Income Model..............74

Financial Assistance, Employment Services, Race/Ethnicity, And Income Model.......................................................... 75

Post-Hoc Analyses.................................................... 79

Post-Hoc Regression Analysis......................................79

Post-Hoc Descriptive Statistics of the Charges that Led to Incarcerations...83 


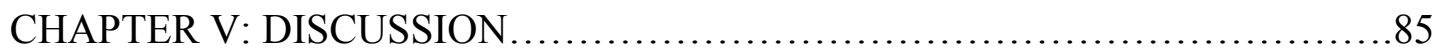

Financial Assistance and Reductions in Recidivism.........................85

Substance Use Treatment and Recidivism Outcomes......................87

Mental Health Treatment and Recidivism Outcomes.......................88

Treating Substance Use and Mental Health Issues...........................89

Race/Ethnicity and Probation.........................................91

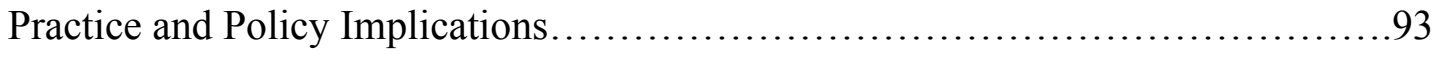

Expanding Affordable Evidence Based Treatment.........................93

Altering Supervision Procedures....................................... 95

Expanding Access to Financial Assistance and Employment

Opportunities........................................................ 96

Eliminating Racially Discriminatory Policing.............................97

Implications for Social Work Practice....................................99

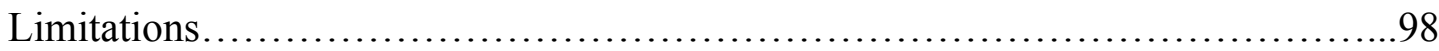

Lacking Information on the Types of Interventions......................98

Effects of Probation Officers on Recidivism Outcomes......................99

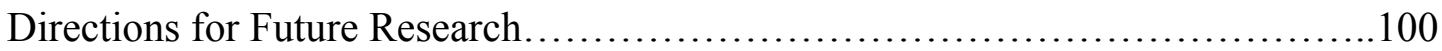

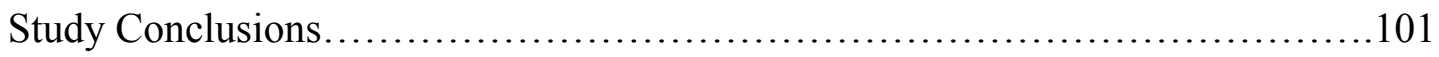

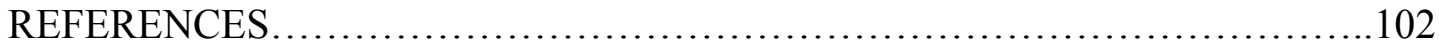

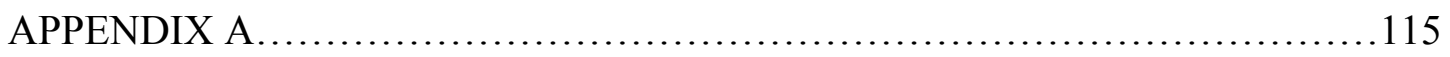

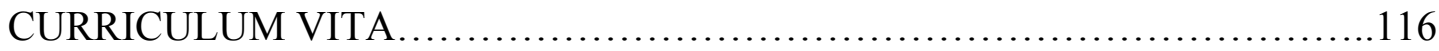


TABLE

\section{LIST OF TABLES}

1. Comparisons of Missing and Non-Missing Race/Ethnicity and

Income Variables.

2. Comparison of Missing and Non-Missing Substance Use Treatment

Variables........................................................64

3. Comparison of Missing and Non-Missing Mental Health Treatment

Variables......................................................66

4. Comparisons of Missing and Non-Missing Poverty Reduction

Service Variables...............................................68

5. Sociodemographic Variables.......................................... 74

6. Substance Use Among the Participants................................ 75

7. Victimization Histories......................................... 76

8. Bivariate Differences Among Women Who Did and Did Not Recidivate.....78

9. Final Logistic Regression Models Predicting Recidivism...................85

10. Final Logistic Regression Post Hoc Model Predicting Recidivism...........89

11. Post-Hoc Descriptive Statistics of the Charges that Led to Incarcerations....91

A1. Bivariate Racial Differences Between Income and Education.............109 


\section{CHAPTER I}

\section{STATEMENT OF THE PROBLEM}

Probation has become one of the main contributing factors to the mass incarceration of women in the United States (U.S.). While the U.S. is noted for having the largest population of female prisoners in the world, the vast majority of women within the country's criminal justice system are on probation. Currently, 947,450 women are on probation in the U.S., which represents $80 \%$ of the overall female criminal justice population (Kaeble \& Bonczar, 2016). Although probation was established to function as a diversion for prison-bound cases in which offenders are instead supervised in their communities, its effectiveness as an alternative to incarceration women remains doubtful (Phelps, 2013). More specifically, several national, state, and regional studies have identified recidivism rates (i.e. incarcerations) among women on probation to range from 21\% to 46\% (Langan \& Cunnif, 1992; Petersilia, 1997; Steinmetz \& Henderson, 2016; Vera Institute of Justice, 2016). As a result, probation frequently operates as a link to incarceration for female offenders rather than a substitute.

Currently, the number of studies examining the factors that contribute to probation recidivism for women is rather limited (Phelps, 2013). Over the previous decade, however, scholars have started to investigate the link between probation and incarceration in more detail. The findings from this research, although limited to only three studies, indicate that several issues common to female offenders, including 
substance use disorders, illicit drug use, victimization histories, mental illness, and poverty, present significant challenges to the successful completion of a probation sentence (Holtfreter, Reisig, \& Morash, 2004; Olson, Lurigio, \& Alderden, 2003; Salisbury \& Van Voorhis, 2009). More specifically, the requirements of probation sentences, which include abstaining from drug use, participating in mandatory substance use and/or mental health treatment, paying supervision fees and/or court fines, and travelling regularly to meetings, are more difficult for female probationers to meet given the high rates of substance use disorders, mental health issues, and poverty among the population (ACLU, 2016; Phelps, 2013; Salisbury \& Van Voorhis, 2009; Kentucky Department of Probation and Parole, n.d.).

However, despite the numerous problems that women can experience while on probation, they often encounter difficulties accessing services to address issues affecting their ability to have successful criminal justice outcomes, even though participating in these treatments are usually conditions for completing sentences (Marlowe, 2003). For instance, instead of providing probationers with services for issues such as substance use, mental illness, and poverty, the criminal justice system typically emphasizes punishing offenders for violating the conditions of their community supervision (ACLU, 2016; Marlowe, 2003; PEW Center on the States, 2011; Phelps, 2013; Taxman, Perdoni, \& Harrison, 2007). As a result, female probationers can be left in the precarious position of experiencing issues that make completing probation more difficult yet lacking access to treatment services to assist in improving their criminal justice outcomes (Phelps, 2013; Salisbury \& Van Voorhis, 2009; Kentucky Department of Probation and Parole, n.d.). 
In addition to the issues that commonly affect female probationers as an overall population, there is a long history of racially discriminatory policies directed toward African Americans by the U.S. criminal justice system (ACLU, 2016; Alexander, 2010; Mauer \& King, 2007). While most of the research on racial discrimination in the criminal justice system focuses on the incarceration population, the available evidence indicates that African Americans experience unique challenges while on probation as well (ACLU, 2016; Alexander, 2010; Phelps, 2013; Steinmetz \& Henderson, 2016). For instance, the current and historic criminal justice policies in the U.S. lead to the over-policing and racial profiling of African Americans, which results in a disproportionate number of individuals within the population being sentenced to probation (Alexander, 2010; Mauer \& King, 2007; Zinn, 1980). As evidence, African Americans comprise $30 \%$ of the U.S. probation population yet only $13 \%$ of the general population, in addition to $30 \%$ of probationers in the Jefferson County region of Kentucky where the participants in this dissertation study resided, but only $22 \%$ of the county's total population (Kaeble \& Bonczar, 2016; Personal Communication, 2017).

African Americans are also more likely to encounter stricter supervision requirements during their probation sentences (Alexander, 2010; Mauer \& King, 2007; Steinmetz \& Henderson, 2016). More specifically, evidence suggests that African American probationers are placed on higher levels of community supervision than other racial groups, which intensifies the monitoring they receive from probation officers and consequently increases their chances of recidivating (Alexander, 2010; Mauer \& King, 2007; Steinmetz \& Henderson, 2016). Furthermore, the structural inequalities in U.S. society, including educational and economic systems that provide less education and 
fewer job opportunities to African Americans, result in racial disparities in educational attainment and income, which increases the likelihood of poverty and could therefore lead to additional difficulties meeting the financial requirements of probation (Alexander, 2010; Chang, 2010; Collins \& Bilge, 2016; Zinn, 1980)

Furthermore, African Americans may encounter additional barriers to accessing treatment services during probation sentences. Specifically, studies including both the probation population and general public indicate that African Americans have less access to mental health and substance use treatment services than other racial groups (Cummings, Wen, Ko, \& Druss, 2014; Wells, Klap, Koike, \& Sherbourne, 2001). To date, however, no research has examined whether racial disparities in treatment access affects the probation outcomes of African Americans, which raises questions about how this could affects criminal justice outcomes.

\section{Importance of Feminist Criminology}

The field of feminist criminology was developed to highlight the gender biases in the criminal justice system and bring greater attention to issues commonly experienced by female offenders (Chesney-Lind \& Pasko, 2013). Chesney-Lind \& Pasko (2013) presented several core principles of feminist criminology, which include the following: (1) criminology researchers often ignore the topic of female crime and trivialize the victimization histories frequent among women offenders; (2) most crime theories focus on male identities and therefore fail to recognize the "relations of dominance, power, and inequality between men and women" (Chesney-Lind \& Pasko, 2013, p. 3); and (3) the treatment services provided to female offenders by the criminal justice system, if they are available at all, rarely take into consideration the unique needs of the population 
including disproportionate rates of victimization, substance use disorders, illicit drug use, mental illness, and poverty (Chesney-Lind \& Pasko, 2013). As such, the aim of feminist criminology is to understand the factors that affect female crime and evaluate the services received by female offenders during their sentences (Chesney-Lind \& Pasko, 2013).

Two theoretical frameworks that have previously been utilized in feminist criminology research, the pathways perspective and social and human capital theories, will be applied to this study in order to evaluate the impact of treatment services on the recidivism outcomes of female probationers (Chesney-Lind, 2000; Chesney-Lind \& Pasko, 2013; Holtfreter, Reisig, \& Morash, 2004; Olson, Lurigio, \& Alderden, 2003; Salisbury \& Van Voorhis, 2009). While a more detailed explanation of these theories is provided in Chapter 2, to contextualize their relevance to this dissertation study, a brief account will be given here. First, the pathways perspective describes a common path taken by female offenders to the criminal justice system, which frequently includes childhood victimization, intimate partner violence, mental illness, addiction, and poverty (Bloom, Owen, \& Covington, 2003; Chesney-Lind, 2000; Chesney-Lind \& Pasko; Covington, 2008; Daly, 1992, 1994; Salisbury \& Van Voorhis, 2009). Secondly, social and human capital theories explain how educational deficits, limited job skills, and a lack of social connections contribute to the poverty, lawbreaking behaviors, and recidivism common among female offenders (Coleman, 1988; Reisig, Holtfreter, \& Morash, 2002; Holftreter et al., 2004; Salisbury \& Van Voorhis, 2009).

While both the pathways perspective and social and human capital theories describe multiple issues that affect the occurrence of female crime and recidivism, each theory largely ignores the topic of race/ethnicity even though several minority 
populations, including African Americans, Latinos, and Native Americans, are overrepresented in the criminal justice population (Alexander, 2010; ACLU, 2016; Vera Institute of Justice, 2016). Therefore, this dissertation will apply race/ethnicity to its conceptual framework in several ways. First, based on their over-representation in the national probation population in the Jefferson County, KY area in which this study was conducted (Kaeble \& Bonczar, 2016; Personal Communication, 2017), African American female offenders may disproportionately encounter the issues described in the pathways perspective and social and human capital theories as common to women offenders. Secondly, the African Americans experience fewer economic opportunities and more punitive criminal justice policies and will subsequently be referenced in order to examine any racial disparities in recidivism outcomes among female probationers (Chang, 2010; Collins \& Bilge, 2016; National Women's Law Center, 2017; Zinn, 1980).

\section{The Paradox of Probation}

Over the previous decade, the politics of punishment in the U.S. has started to shift from incarceration toward more noncustodial options, most often in the form of probation supervision (Phelps, 2013). Driven in large part by the state budget crises occurring across the country, the idea has grown in prominence that diverting prisonbound cases to probation can reduce recidivism rates at a portion of the cost of incarceration $^{1}$ (PEW Center on the States, 2011; Phelps, 2013). Nevertheless, despite the original intention of functioning as a cheaper alternative to incarceration, probation has actually increased the prison and jail populations in many regions of the U.S. (Phelps,

\footnotetext{
${ }^{1}$ According the PEW Center on the States (2011), incarcerating a person is 20 times more costly per day than supervising them in the community.
} 
2013; Vera Institute of Justice, 2016). The relationship between probation and incarceration is driven by several factors. First, probationers often experience difficulties meeting the conditions of their supervision and therefore are levied with technical violations and revocations that result in prison or jail sentences (Phelps, 2013; Vera Institute of Justice, 2016). Secondly, numerous criminal offenses that were previously settled with fines now lead to probation sentences, which draws more low-level offenders into the criminal justice system who struggle to meet the requirements of their supervision $^{2}$ and subsequently become incarcerated (Phelps, 2013; Tonry \& Lynch, 1996).

Furthermore, the ability for probation to function as an effective alternative to incarceration depends on the treatment services provided at community-based agencies (Phelps, 2013). In fact, the reception of treatment services could be particularly important for female probationers given the high rates of victimization histories, substance use disorders, mental illness, and poverty among the population (Chesney-Lind \& Pasko, 2013). However, despite the recent expansion of treatment programs for substance use and mental health, several problems have been noted in regard to the interventions currently available to probationers. Specifically, the probation population often encounters difficulties accessing treatment services and several of the interventions currently available either lack an evidence base or have punitive policies that incarcerate offenders for failing drug tests even though relapse is a common aspect of recovery (ACLU, 2016; Marlowe, 2003; Taxman et al., 2007).

\footnotetext{
${ }^{2}$ Supervision requirements for probation vary across jurisdictions, but generally include requirements to abstain from drugs and alcohol, maintain employment, meet regularly with probation officers, and pay supervision fees.
} 
Furthermore, research on the services provided to female probationers is largely absent from the existing literature. Only one study has analyzed the affect of a drug treatment intervention for women on probation and thus far none have investigated programs that address mental health or poverty (Shaffer, Hartmen, \& Listwan, 2009). Despite this gap in the literature, research indicates that services for women prisoners can reduce post-release drug use, trauma symptoms, and recidivism, and could therefore have a positive impact on female probationers as well (Covington, 2008; Messina, Grella, Cartier, \& Torres, 2010; Swopes, Davis, \& Scholl, 2015; Wolff, Frueh, Shi, \& Schumann, 2012; Zlotnick, Johnson, \& Najavitis, 2009). As such, this dissertation will assess the affect of the services provided to female probationers during their sentences in order to examine the impact on recidivism outcomes (Chesney-Lind \& Pasko, 2013; Covington, 2008; SAMHSA, 2014).

\section{The Present Study}

This dissertation will investigate whether any differences in probation recidivism outcomes occurred between women who received services for issues common to female probationers (e.g., substance use, mental illness, and poverty) and those who did not. Furthermore, given the history of discrimination directed toward African Americans by the U.S. criminal justice system and the racial disparities in treatment access, an additional assessment will be conducted in regard to whether the race/ethnicity of the participant affected recidivism outcomes. Secondary data from the Women's Health Research Study (WHRS), a longitudinal study of 406 victimized women (i.e., experienced physical and/or sexual abuse) on probation and parole in Louisville, KY, will be utilized for these analyses. The inclusion of a sample of women who have all 
experienced victimization is important to the objectives of this study since abuse histories increase the likelihood that a person will develop a mental illness or substance use disorder (Chesney-Lind \& Pasko, 2013; Covington, 2000; SAMHSA, 2014) The primary objectives of the study, which will be expanded on in Chapter 2, are listed below:

Objective 1: To explore the affects that drug treatment service utilization and the race/ethnicity of the participant have on the occurrences of probation recidivism among a sample of victimized women on probation.

Objective 2: To explore the affects that mental health treatment service utilization and the race/ethnicity of the participant have on the occurrences of probation recidivism among a sample of victimized women on probation.

Objective 3: To explore the affects that employment services, government financial assistance, and the race/ethnicity of the participant have on the occurrences of probation recidivism among a sample of victimized women on probation. 


\section{CHAPTER II}

\section{LITERATURE REVIEW}

This chapter includes an examination of the research pertaining to female probationers in the U.S. To evaluate the effectiveness of probation as a diversion for incarceration, several issues influential to the criminal justice outcomes of female probationers will be reviewed. Specifically, this chapter will examine how issues common to women on probation, such as victimization histories, mental illness, substance use disorders, illicit drug use, and poverty, can affect recidivism. In addition, the impact of treatment services on the recidivism outcomes of female probationers will also be outlined. Furthermore, the disproportionate representation of African Americans within the probation population is analyzed in relation to recidivism, racial discrimination, and access to treatment services.

To begin, the pathways perspective and social and human capital theories are presented to provide a theoretical framework for this dissertation (Bourdieu, 1995; Chesney-Lind \& Pasko, 2013; Coleman, 1988; Daly, 1992, 1994; Lin, 1999; Portes, 1999). Second, the term cumulative disadvantage is employed as an organizing principle for reviewing the research on how victimization histories, mental illness, substance use, and poverty can impact the criminal justice involvement of female offenders. Third, the issue of racial discrimination within the criminal justice system will be assessed. Fourth, 
female probation recidivism is examined through evaluating data on the frequency of the event and the factors influencing it. Next, the treatment services provided to female probationers are assessed through reviewing research on the availability and effectiveness of the existing interventions. Finally, the gaps in the current research are explained in order to provide rationale for conducting this dissertation study.

While the objective of this chapter is to review research on women probationers, given the limited amount of data available on the population, studies comprised of parolees and prisoners will be referenced as well. Although prison and parole represent separate divisions of the criminal justice system, there are several reasons for including research on these populations. First, female offenders often experience similar issues regardless of the type of supervision they are under, including high rates of substance use disorders, physical and/or sexual victimization histories, mental illness, educational deficits, and poverty (Bloom, Owen, \& Covington, 2003; Chesney-Lind \& Pasko, 2013; Greenfeld \& Snell, 2001). Secondly, probationers and parolees are generally placed on comparable forms of community supervision and therefore encounter similar requirements for completing their sentences (PEW Center on the States, 2011; Phelps, 2013).

\section{Conceptual Framework}

The following section describes the conceptual framework for this dissertation. To begin, the pathways perspective is referenced to describe the relationship between recidivism and several issues common to women probationers, including victimization histories, substance use disorders, mental illness, and poverty. In addition, social and human capital theories will be utilized to assess the affect that poverty, educational 
deficits, and limited social connections have on female crime and recidivism. Lastly, the disproportionate representation of African Americans in the criminal justice system will be considered within the theoretical framework of this dissertation in order to examine its affect on recidivism and access to treatment services.

\section{The Pathways Perspective}

The pathways perspective describes a distinct path taken by women to the criminal justice system. Most specifically, pathways research examines the relationship between female crime and several issues common to women offenders, such as victimization histories, mental illness, substance use and/or addiction, and poverty (Bloom, Owen, \& Covington, 2003; Chesney-Lind \& Pasko, 2013). Several feminist criminologists were instrumental to the development of the pathways perspective. Daly's contributions $(1992,1994)$ included establishing five distinct paths to female crime based on reviewing the records of eighty women in felony court. Daly's $(1992,1994)$ pathways included: (1) "harmed and harming women" who were abused or neglected during childhood and developed behavioral problems, mental illnesses, and/or addictions that contributed to violent behavior; (2) "battered women" who committed violent crimes in response to physical attacks from their current or former husbands or boyfriends; (3) "street women" who ran away from abusive childhood homes and then developed addiction problems, which subsequently led to lawbreaking behaviors such as drug dealing, theft, robbery, or sex work, often to support their drug dependence; (4) "drugconnected" women who sold or used drugs, usually in connection with their boyfriends; and (5) "other" women who did not fit into the previous four categories but otherwise engaged in crime for financial reasons (Daly, 1992, 1994). 
In addition to the five pathways to crime, Daly $(1992,1994)$ also identified several similarities among the court records. Specifically, nearly all of the women in the sample experienced the following issues: drug or alcohol addiction, psychological problems including depression, aggressive personalities, or suicidal ideations, having drug-addicted parents, and lacking a high school degree (Daly, 1992, 1994). While Daly's work was fundamental to the development of the pathways perspective and remains influential today, one limitation was the use of secondhand court files as the primary source of data (Wattanaporn \& Holtfreter, 2014).

Chesney-Lind (1997; 2000; Chesney-Lind \& Pasko, 2013) is also noted for contributing to the pathways perspective through emphasizing the relationship between victimization, depression, drug use, and female crime. According to Chesney-Lind (1997, 2000, Chesney-Lind \& Pasko, 2013), justice-involved women often develop depression and other mood disorders as a result of their abuse histories, which can lead them to selfmedicate with drugs and alcohol. In addition, Chesney-Lind (2000) identified a female path to crime that involves escaping abusive childhood homes and becoming involved in the juvenile justice system, which can result in one or more of the following events: (1) homelessness; (2) engaging in prostitution to support a drug addiction; and/or (3) becoming incarcerated for violating the conditions of community supervision.

This dissertation will incorporate the pathways perspective in several ways. First, the aforementioned issues related to substance use, mental illness, and poverty can increase the likelihood that female probationers will experience recidivism, and therefore provides reason to investigate whether treatment service will affect criminal justice outcomes (Salisbury \& Van Voorhis, 2009; Reisig et al., 2003; Olsen et al., 2004). The 
second application of the pathways perspective involves each of the participants in this study's sample experiencing at least one lifetime encounter with physical or sexual abuse. More specifically, given the cognitive, emotional, and behavioral issues that can result from physical or sexual abuse, this provides rationale for exploring whether receiving treatment services affects the recidivism outcomes of the participants (Chesney-Lind, 2000; Chesney-Lind \& Pasko, 2013; Daly, 1992, 1994; Olson et al., 2004; Reisig et al., 2003; Salisbury \& Van Voorhis, 2009).

\section{Social Capital and Human Capital Theories}

Social and human capital theories are utilized in this dissertation to examine the affects of poverty on the occurrences of recidivism among the participants. Social capital is based on the notion that relationships yield returns for individuals (Coleman, 1988; Bourdieu, 1986; Lin, 1999; Portes, 1998). In spite of this organizing principle, multiple scholars have presented their own definitions of social capital. For example, both Coleman (1988) and Bourdieu (1986) define social capital as the resources available to a person through connections within their social groups that subsequently provide support in reaching otherwise unobtainable goals. Coleman (1988) also describes social capital as the emotional support and employment opportunities that a person receives from within their social networks.

In addition, Portes (1998) presented three specific types of social capital: (1) social control, which involves individuals living in environments where authority figures provide them with support following rules; (2) family support in which family encouragement increases a person's educational success and employment opportunities;

(3) relationships with extrafamiliar networks which help a person find employment 
through connections in their social groups. However, Portes (1998) notes an unequal distribution of social capital depending on a person's socioeconomic position. Bourdieu (1986) expanded on this view by developing the term symbolic capital, which describes one group of people exerting power over another.

Several scholars have noted a relationship between social capital and human capital. Human capital, which is defined as a person's educational level and amount of marketable job skills, helps an individual develop the credentials to attain well-paying employment and economic stability (Coleman, 1988). Coleman (1988) asserts that a person's amount of social capital is directly related to their level of human capital. For example, when an individual experiences social conditions that enhance their psychological security and self-efficacy (i.e., social capital), it assists them in developing the job skills (i.e., human capital) to obtain employment and subsequently reach financial stability (Coleman, 1988).

Scholars have identified that women offenders frequently encounter deficits in human capital (Reisig et al., 2003). In particular, these shortages in human capital have been noted to result from family members recruiting them to participate in drug dealing and/or theft, living in impoverished communities with limited educational and job opportunities, residing in neighborhoods that are disrupted by over-policing, and having smaller social networks that provide fewer connections for finding employment (Owen \& Bloom, 1995; Reisig et al., 2002; Rose \& Clear, 1998). As a consequence, female offenders often have fewer economic and social options and therefore turn to relationships that facilitate lawbreaking behavior (Reisig et al., 2002). This dissertation will apply social and human capital theories to examine whether receiving services to 
assist with finding employment or financial stability affects recidivism outcomes. More specifically, since research indicates that living in poverty increases lawbreaking behaviors and recidivism for female probationers, receiving services to reduce financial challenges could improve criminal justice outcomes (Reisig et al., 2003; Steffensmeier, 1993; Steffensmeier \& Haynie, 2000).

\section{Applying Race/Ethnicity to the Conceptual Framework}

As stated in Chapter 1, African Americans are over-represented in the probation populations of both the overall U.S. and the Jefferson County, KY area in which the women in this study reside (Kaeble \& Bonczar, 2016; Kentucky Department of Probation and Parole, 2017). However, the pathways perspective and social and human capital theories largely exclude discussions pertaining to race/ethnicity. Nevertheless, given the over-representation of African American women in the probation population, this dissertation will apply the topic of race/ethnicity in several ways. First, due to their disproportionate representation in the probation population, African American offenders may be at a greater risk of experiencing the issues common to female offenders, including victimization histories, substance use disorders, mental illnesses, and poverty. Second, the systemic inequalities in U.S. society that result in discriminatory policing, harsher criminal justice punishments, and fewer economic opportunities for African Americans could produce greater challenges meeting the requirements of probation sentences (Alexander, 2010; Collins \& Bilge, 2016; Mauer \& King, 2007; Zinn, 1980). Third, the racial disparities in access to treatment for African Americans will be applied in order to evaluate whether this has any affect on recidivism outcomes. 


\section{Cumulative Disadvantage}

Justice-involved women often encounter cumulative disadvantage as a result of their frequent experiences with victimization histories, mental illness, drug addiction, poverty, and educational deficits (Mallicoat, 2011). Merton (1988) describes cumulative disadvantage as circumstances whereby "capacity, structural location, and available resources make for successive increments of advantage such that the gaps between the haves and the have-nots widen" (p. 606). Cumulative disadvantage will therefore be utilized in this chapter to expand on the topics described in the previous section as influential to female crime and recidivism. In particular, several disadvantages will be described, including victimization histories, mental illness, substance use disorders/illicit drug use, and poverty. Each issue will be explained utilizing the following information: a) the frequency with which it occurs; b) how it affects female probationers in ways that could require mental health treatment, substance use treatment, employment services, or financial assistance; c) how it is experienced among female probationers at disproportionate rates; and d) how it affects lawbreaking behavior. Taken together, this information will ultimately provide context for investigating the relationship between treatment services and recidivism.

\section{Occurrences of Victimization}

The lives of female probationers often include histories of severe, prolonged, and deliberate abuse, most frequently through physical and/or sexual victimization (Bloom, Owen, \& Covington, 2003; Chesney-Lind \& Pasko, 2013; Daly, 1992, 1994). According to the Bureau of Justice Statistics (2001), 41\% of female probationers in the U.S. have had at least one direct encounter with physical and/or sexual abuse in their lifetime. This 
level of victimization is more common to female probationers in comparison to their male equivalents, as $9 \%$ of men on probation have reported physical and/or sexual abuse histories (Harlow, 2003).

\section{Health Issues Associated with Victimization}

Female probationers are at an increased risk of encountering numerous health problems through having frequent histories of physical and/or sexual victimization (Bloom, Owen, \& Covington, 2003; Chesney-Lind, 2000; Chesney-Lind \& Pasko, 2013). Although the health problems that can result from victimization are only more likely to occur as opposed to certain, female probationers still have a greater risk of developing multiple cognitive, behavioral, and emotional issues (Substance Abuse and Mental Health Administration [SAMHSA], 2014). According to SAMHSA (2014), the cognitive issues include false rationalizations, lacking social awareness, excessive guilt, hallucinations, delusions, and/or invasive thoughts; the behavioral problems encompass self-medicating with drugs or alcohol, avoidance, compulsive and/or impulsive actions, and/or self-harm; and the emotional issues include anger, anxiety, sadness, shame, and/or numbness (SAMHSA, 2014).

Several of the cognitive, behavioral, and emotional issues listed above are also indicative of mental illness. According to the National Survey on Drug Use and Health [NSDUH], $46 \%$ of female probationers have a $D S M-V$ diagnosed mental, behavioral, or emotional disorder (Center for Behavioral Health Statistics and Quality, 2015). This frequency of mental illness is more common to female probationers compared to men on probation and women in the general population. Specifically, $27 \%$ of men on probation and $20 \%$ of women in the general population have a diagnosed mental illness (Center for 
Behavioral Health Statistics and Quality, 2015). The NSDUH study also identified that $28.6 \%$ of women on probation have seriously considered committing suicide, which is more than twice the rate of both male probationers and females from the general U.S. population (Center for Behavioral Health Statistics and Quality, 2015).

\section{Victimization and Female Crime}

The abuse histories common to women offenders increase their likelihood of engaging in lawbreaking behavior (Chesney-Lind, 2000; Chesney-Lind \& Pasko. 2013; Daly, 1992, 1994). In fact, one of the main reasons women are charged with violent crimes is through responding to attacks from intimate partners (Chesney-Lind \& Pasko, 2013). For instance, one study found that $58 \%$ of the violent crimes committed by women occurred during domestic violence incidents, and in over one-third of those cases, the accused female was the one who phoned the police (Comack, Chopyk, \& Wood, 2000). In addition, Daly's aforementioned work $(1992,1994)$ on the pathways to crime illustrated that female offenders frequently commit violent crimes in order to escape abusive relationships.

\section{Occurrences of Substance Use}

The profiles of women probationers often include substance use disorders and recent illicit drug use (Chesney-Lind \& Pasko, 2013; Covington, 2008). According to the NSDUH, $29 \%$ of female probationers in the U.S. have a $D S M-V$ diagnosed substance use disorder, which occurs when drug or alcohol use leads to health problems, social impairments, and difficulties functioning at work, school, or home $\mathrm{e}^{3}$ (Center for Behavioral Health Statistics and Quality, 2015). In addition, the NSDUH also identified

\footnotetext{
${ }^{3}$ This percentage indicates that nearly 300,000 women on probation have a substance use disorders, which is a greater number than the entire female jail and prison populations.
} 
that $28.6 \%$ of female probationers used illicit drugs at least once in the previous month (Center for Behavioral Health Statistics and Quality, 2015). This frequency of substance use disorders and illicit drug use is significantly more common among female probationers than women in the general population. Specifically, female probationers are diagnosed with substance use disorders six times more often than women in the general population and use illicit drugs four times more often (Center for Behavioral Health Statistics, 2015).

\section{Health Issues Associated with Substance Use}

The high rate of substance use disorders among female probationers increases the likelihood of developing several health issues (Volkow, Koob, \& McLellan, 2016). More specifically, research on the brain disease model of addiction explains how substance abuse or dependence (e.g., the criteria for a substance use disorder diagnosis) can significantly impair a person's brain functioning (Volkow et al., 2016). For instance, substance abuse or dependence often results in an individual experiencing decreases in their dopamine production, which negatively affects the brain's amygdala functioning (Volkow et al., 2016). As a consequence, an individual with a substance use disorder is significantly more likely to encounter problems with emotional regulation and decisionmaking, in addition to experiencing withdrawal symptoms that can provoke further drug use (Volkow et al., 2016).

\section{Substance Use and Female Crime}

Evidence suggests that drug and/or alcohol use significantly increases the occurrence of female crime. A national study by the Bureau of Justice Statistics identified that $25 \%$ of female probationers were under the influence of drugs or alcohol while 
committing the crime that led to their current probation sentence (Greenfeld \& Snell, 2001). In addition, scholars have also noted a direct relationship between female crime and drug use. More specifically, one of the main reasons that women engage in lawbreaking behavior is to obtain money for drugs (Uggen \& Thompson, 2003). For instance, a qualitative study including 276 parolees, half of whom were women, illustrated that most participants engaged in crime in order to procure money for drugs (Jamieson, McIvor, \& Murray, 1999). Similarly, another qualitative study of women parolees found the participants largely attributed their lawbreaking behaviors to needing money for drugs (Taylor, 2008).

\section{Occurrences of Poverty}

Poverty is a common characteristic across the criminal justice population, but it is particularly prevalent among women offenders (Bloom, Owen, \& Covington, 2003; Chesney-Lind, 2000; Chesney-Lind \& Pasko, 2013; Richie, 2001). Most of the current research on the economic conditions of the criminal justice population focuses on prisoners, but the available evidence indicates that probationers experience financial challenges as well. For example, a 2016 statewide study in Massachusetts identified probationers were $88 \%$ more likely to live in the state's poorer districts than the wealthier ones (Sawyer, 2017). Neither national nor regional data is currently available on the specific financial conditions of female probationers, but studies among women prisoners have identified higher rates of economic disadvantage compared to men in prison and women from the general population. A national study illustrated that the average yearly incomes of women prisoners prior to their incarcerations were $\$ 10,000$ less than non- 
incarcerated females, and \$6,000 less than incarcerated men (Prison Policy Institute, 2015).

The high rates of poverty among female offenders have been identified to result from educational deficits, limited employment opportunities, felony-level convictions, and single parenthood (Bloom, Owen, \& Covington, 2003; Chesney-Lind \& Pasko, 2013; Holtfreter et al.; 2004; Reisig et al.; 2002). In regard to educational deficits, a national study identified that $40 \%$ of female probationers did not complete high school and only $24 \%$ attended college or post-secondary career training programs (Harlow, 2003). As a consequence, female probationers typically develop fewer marketable skills (i.e., human capital), which often limit their employment options to low wage jobs with unstable hours and no benefits (Harlow, 2003; Holtfreter et al., 2004; Opsal, 2012, 2015; Reisig et al., 2002). For instance, Opsal $(2012,2015)$ conducted a qualitative study of women parolees and found that most participants were employed at minimum wage jobs and lived paycheck-to-paycheck, and their frustrations with the marginal pay and sporadic work hours often resulted in them quitting (Opsal, 2012, 2015).

Women offenders also encounter economic challenges through having felonylevel drug convictions, which is particularly relevant to the present research since drugrelated offenses represent the number one reason a person is sentenced to probation (ACLU, 2016). More specifically, felony drug convictions limit a person's access to poverty reduction programs such as the Supplemental Nutrition Assistance Program (SNAP), Temporary Assistance for Needy Families (TANF), and public housing, in addition to bans from acquiring numerous professional licenses (Allard, 2002; Sentencing Project, 2015). Although each state in the U.S. has the option whether to enact these 
penalties or not, over half enforce either full or partial bans on SNAP, TANF, and public housing, which is especially important to female probationers since women represent $90 \%$ of national TANF recipients and receive SNAP benefits twice as often as men (Sentencing Project, 2015).

Female probationers may encounter additional economic challenges from the financial responsibilities associated with parenting. According to the Bureau of Justice Statistics, $60 \%$ of women on probation are raising a minor child (Greenfeld \& Snell, 2001). While national data on the percentage of male probationers who are parents is currently unavailable, evidence from other segments of the criminal justice population indicates men are less likely than women to serve as the primary caregivers of their children. Specifically, a national study illustrated that $41 \%$ of women in state prison were raising a child before their incarceration, compared to only $29 \%$ of men (Glaze \& Maruschak, 2010). As such, female probationers have a greater chance of experiencing the financial responsibilities associated with parenthood. For example, a qualitative study of women parolees found the participants encountered significant financial difficulties through the costs associated with raising a child (Johnson, 2014).

\section{Poverty and Female Crime}

The financial challenges common to female offenders also affect the occurrences

of lawbreaking behavior. Notably, Steffensmeier's (1993; Steffensmeier \& Haynie, 2000) research is relevant to the relationship between poverty and female crime. A national study conducted by Steffensmeier \& Haynie (2000) identified that women in poorer regions of the U.S. are significantly more likely to engage in economically motivated crimes such as robbery, burglary, and larceny. A second national study by Steffensmeier 
(1993) demonstrated that living in poverty significantly increased the likelihood that women would commit shoplifting crimes. Furthermore, each of Daly's $(1992,1994)$ pathways to crime mentioned poverty as a motivating factor to criminality among women offenders.

\section{Racial Disproportionality Among Probationers}

In addition to the issues affecting female probationers as an overall population, race/ethnicity is also noted as a significant factor to probation involvement and recidivism. This dissertation focuses on the racial disproportionality among African American probationers given their over-representation in the Jefferson County, KY and national criminal justice populations (Kentucky Department of Probation and Parole, 2017). As stated in Chapter 1, African Americans represent $30 \%$ of women on probation in Jefferson County, KY, but only $20 \%$ of the county's overall female population (Kentucky Department of Probation and Parole, 2017). Also, African Americans comprise $30 \%$ of probationers in the U.S. despite comprising only $13 \%$ of the country's general population (Kaebel \& Bonczar, 2016; U.S. Census, 2016).

The disproportionate representation of African Americans in the U.S. criminal justice population is related to a series of discriminatory policies implemented over the previous four decades, which are collectively referred to as the "war on drugs" (Alexander, 2010; Mauer \& King, 2007). Although most research pertaining to the war on drugs is centered on racial disparities in prison sentences for drug-related convictions, particularly in seminal work on "mass incarceration" by Alexander ${ }^{4}(2010)$ and the

\footnotetext{
${ }^{4}$ Michelle Alexander's book, The New Jim Crow: Mass Incarceration in the Age of Colorblindedness, outlines various policies that increase the racial disparities in prison terms for African Americans in comparison to other racial groups.
} 
Sentencing Project ${ }^{5}$ (2007; 2010; 2016), African Americans on probation are disproportionately affected by these policies as well. The connection between racial discrimination and probation can be linked to disparities in arrests for drug possession offenses, which represent the number one criminal conviction among probationers (ACLU, 2016). ${ }^{6}$ For example, despite the similarities in illicit drug use across different racial groups in the U.S., African Americans are arrested for drug possession offenses three times more often than Whites (ACLU, 2016).

In regard to the targeting of African Americans for drug-related offenses, the racial profiling and aggressive policing practices employed by police departments across the country are major factors contributing to the racial disproportionately within the probation population (Alexander, 2010; Sentencing Project, 2015). Evidence suggests that areas in which African Americans represent the majority of residents are placed under near constant police surveillance ${ }^{7}$, often so officers can meet the mandatory arrest quotas set by their departments $^{8}$ (ACLU, 2016; Alexander, 2010; Sentencing Project, 2015). Although the targeting of African American neighborhoods by police for drugrelated offenses is an under-researched topic, a citywide study in Seattle provides

${ }^{5}$ The Sentencing Project is a research organization that for over 30 years has worked on its stated goal of promoting reforms in order to make the criminal justice system more fair and effective.

${ }^{6}$ African Americans represent $14 \%$ of drug users in the United States, which is nearly equivalent to their percentage of the country's overall population.

${ }^{7}$ Racial discrimination in housing policies is noted as contributing to the development of racially segregated neighborhoods.

${ }^{8}$ State and local governments often place mandates on police department to make a minimum number of arrests, which guarantees income from the court fees and fines given to offenders. 
evidence of its occurrence. The study identified that African Americans were convicted of crack cocaine possession offenses significantly more often than other racial groups even though Whites represented the majority of crack cocaine users in the city (Beckett, Nyrop, Pfingst, \& Bowen, 2005).

Furthermore, two specific policing strategies, stop-and-frisks and pre-text stops, have been noted to increase the likelihood that African Americans will be arrested for drug-related offenses (Alexander, 2010; Sentencing Project, 2016). Stop-and-frisks authorize police to search a person for illicit drugs even in the absence of probable cause, while pre-text stops involve officers using exaggerated traffic offenses as excuses to pull over motorists and search their vehicles (ACLU, 2016; Alexander, 2010; Sentencing Project, 2016). Several studies on both stop-and-frisks and pre-text stops have demonstrated that African Americans are arrested significantly more often for drugrelated offenses through these policing strategies. A study of the New York Police Department found that African Americans represented $82 \%$ of the individuals arrested for misdemeanor drug offenses, while vague reasons such as "making furtive movements" were frequently provided as rationale for conducting the searches (Sentencing Project, 2016). Also, multiple studies of police records and highway video footage illustrate that pre-text stops are employed on African American motorists significantly more often than other racial groups (Alexander, 2010; Epp, Maynard-Moody, \& Haidel-Market, 2014 as cited in Sentencing Project, 2015; Durose, Smith, \& Langan, 2007).

\section{Poverty and Race/Ethnicity Among African American Women}

The issue of discrimination toward African Americans by the criminal justice system also extends to the topic of economic inequality. More specifically, the historical 
and present day occurrences of discrimination and oppression in the U.S. can increase the likelihood that African American females are living in poverty (Collins \& Bilge, 2016; Zinn, 1980). For example, African Americans women have a greater likelihood of encountering economic disadvantages through having fewer economic and educational opportunities (Collins \& Bilge, 2016; Zinn, 1980). Two recent national studies provide evidence of the economic marginalization of African American women. Chang (2010) found that African American women have nearly 40 times less wealth than White men and 7 times less financial wealth than White women (Chang, 2010). Also, the National Women's Law Center (2017) identified that Black women make 63 cents on the dollar in comparison to White men. This information provides additional rationale to investigate the relationship between race/ethnicity and poverty on the probation outcomes of female offenders.

\section{Probation Recidivism Among Women}

As stated in Chapter 1, despite the intention of functioning as a diversion for incarceration, evidence suggests that probation increases the prison and jail populations in many regions of the U.S. (Greenfeld \& Snell, 2001; Justice Center, 2013; Kentucky Department of Probation and Parole, 2017; Langan \& Cunniff, 1992; Phelps, 2013; Vera Institute of Justice, 2016). However, the amount of research that specifically examines the probation recidivism rates of women is limited. There are several possible explanations for this shortage of data. First, most research on recidivism includes samples of parolees or individuals recently released from prison ${ }^{9}$ (Steinmetz \& Henderson, 2016).

\footnotetext{
${ }^{9}$ Two national recidivism studies on female ex-prisoners have been conducted in the last decade, while the last one on probationers was completed in 1994 and did not specify between different genders.
} 
Secondly, recidivism studies primarily have samples of men or combinations of males and females (Steinmetz \& Henderson, 2016). As a result, after a search of the available literature, only three studies measuring the probation recidivism rates of women were located, in addition to two others with combined samples of males and females. Nonetheless, this research indicates that probation recidivism is a common outcome for female offenders. The findings from the available studies are listed below followed by an explanation of the results.

- In Kentucky, $21 \%$ of the women who were on probation at any point in 2016 became incarcerated that same year (Kentucky Department of Probation and Parole, 2017).

- In 2016, probation or parole violations accounted for the reason why $25 \%$ of women were in Washington D.C. jails, and 20\% in Baltimore jails (Vera Institute of Justice, 2016).

- A 2013 statewide study in Kansas found that $40 \%$ of the prison sentences in the state resulted from probation violations (Justice Center, 2013).

- A national study by the Bureau of Justice Statistics found that after three years $46 \%$ of probationers were either incarcerated or completely missing from the criminal justice system ${ }^{10}$ (Langan \& Cunniff, 1992).

- A national study identified that 1 in 3 female prisoners were on probation before becoming incarcerated (Greenfeld \& Snell, 2001).

While the above studies indicate a link between probation and incarceration, there were several limitations to accurately measuring the specific recidivism outcomes of

\footnotetext{
10 According to the BJS study, probationers were designated as "missing" if the criminal justice system was unable to find them (i.e., they fled from the region or were on the run).
} 
female probationers. Both the Bureau of Justice Statistics study and the Kansas study had samples of men and women, which prevented the ability to examine gender and probation recidivism (Justice Center, 2013; Langan \& Cunniff, 1992). Also, the Baltimore study and Washington D.C. study included samples of probationers and parolees, which restricted the capacity to measure differences in recidivism outcomes between the two types of community supervision (Vera Institute of Justice, 2016). Notwithstanding these limitations, based on the high recidivism rates identified within the existing research, a connection likely exists between probation and incarceration for women offenders (Greenfeld \& Snell, 2001; Langan \& Cunniff, 1992; Justice Center, 2013; Kentucky Department of Probation and Parole, 2017; Vera of Justice Institute, 2016).

\section{Legal Issues Linking Probation and Incarceration}

This section describes the legal pathway that connects probation to incarceration. Since the terms included in this section explain how probation sentences can lead to prison or jail, the information lays a foundation for a forthcoming evaluation of research on the characteristics influencing recidivism among female probationers. The conditions for completing probation sentences are generally similar across different regions of the U.S., but certain variations may exist which requires contextualizing the policies within the jurisdictions where offenders are supervised (Phelps, 2013). In Kentucky, for example, probationers must meet the following requirements in order to complete their supervision: abstaining from drug and alcohol use; taking random drug and alcohol screenings without refusing them; meeting regularly with probation officers; paying supervision fees; paying court fines or restitution fees; maintaining employment or attending school; participating in any court-mandated treatments, such as mental health 
counseling, substance use treatment, or parenting training; maintaining curfew; avoiding association with known felons; and completing community service hours (Kentucky Department of Probation and Parole, n.d.).

Two inter-related legal terms explain the consequences for offenders violating the conditions of their probation supervision. The first term is a technical violation, which probationers receive for failing to meet the requirements of their sentences (PEW Center on the States, 2011; Steinmetz \& Henderson, 2016; Phelps, 2013; Vera Institute of Justice, 2016). The second term is a revocation, which occurs if the technical violation an offender receives conflicts with the requirements of their supervision, and subsequently results in incarceration for the remainder of a sentence (PEW Center on the States, 2011; Phelps, 2013; Steinmetz \& Henderson, 2016; Vera Institute of Justice, 2016).

The consequences for receiving revocations are similar across the U.S. (i.e., incarceration), but the punishments for technical violations vary depending on the specific probation department (ACLU, 2016; Vera Institute of Justice, 2016). In Kentucky, for example, the penalties for technical violations differ in accordance with the level of supervision a probationer is under (i.e., low, moderate, high, or very high) and the type of infraction they receive (Kentucky Department of Probation and Parole, n.d.). The supervision levels are determined by a probationer's score on the risk/needs assessment administered at the start of their sentence, which takes into account prior criminal history and drug and alcohol use histories (Kentucky Department of Probation and Parole, n.d.). Probationers with higher levels of supervision receive more severe punishments for technical violations, while infractions during lower supervision result in placement to the next level (Kentucky Department of Probation and Parole, n.d.). Limited 
research is available on the types of technical violations that result in revocations, but evidence suggests it varies depending on the type of infraction and the decisions of probation officers and judges (ACLU, 2016; Vera Institute of Justice, 2016). A national study by the ACLU (2016) noted that illicit drug use, failure to pay supervision fees, and neglecting to complete court-mandated treatments are the most frequent reasons probationers become incarcerated, while minor offenses such as missed meetings with probation officers can receive more leniency in terms of the punishment (ACLU, 2016; Kentucky Department of Probation and Parole, n.d.).

\section{Factors Influencing Female Probation Recidivism}

The number of studies investigating the factors that affect probation recidivism for women is rather limited, but research suggests that several of the disadvantages common among the population increase the likelihood of incarcerations (Holtfreter, Reisig, \& Morash, 2004; Salisbury \& Van Voorhis, 2009; Olson, Lurigio, \& Alderden, 2003). A search of the relevant academic databases (i.e., Criminal Justice Abstracts, PsychInfo, Sociological Abstracts, Google Scholar, and Academic Search Complete) yielded three peer-reviewed studies analyzing the factors impacting probation recidivism for women. These studies are described below followed by an evaluation of the results. Salisbury \& Van Voorhis (2009) conducted a study of 313 women and the findings identified that participants with the following issues experienced recidivism significantly more often: past or current substance use, depression, anxiety issues, and/or

less educational attainment. Furthermore, a study by Holtfreter, Reisig, \& Morash (2004), which included 134 female probationers, found that participants who were living in poverty recidivated significantly more often (Holtfreter, Reisig, \& Morash, 2004). Also, 
Olson, Lurigio, \& Alderden (2003) conducted a study of 689 women and identified that participants who used illicit drugs during their supervision were twice as likely to become incarcerated (Olson, Lurigio, \& Alderden 2003).

The results above suggest that several issues associated with the disadvantages common to women offenders increase the occurrence of probation recidivism. Two studies indicated that illicit drug use contributed to probation recidivism (Salisbury \& Van Voorhis, 2009; Olson et al, 2003), which is perhaps unsurprising for several reasons. First, using illicit drugs is in direct violation of the conditions of probation supervision and monitored for regularly by probation officers through drug screenings (Kentucky Department of Probation and Parole, n.d.; Phelps, 2013). Second, women offenders are often placed on higher levels of probation supervision as a result of having past or current substance use issues, and therefore can become incarcerated more quickly for positive drug screenings (Chesney-Lind \& Pasko, 2013; Holtfreter et al., 2004).

The findings related to poverty leading to probation recidivism could be explained, at least in part, by the criminal justice system incarcerating probationers for failing to pay their supervision fees. Although the U.S. Supreme Court ruled that probationers should not be incarcerated for failing to pay supervision fees, a recent study found that certain courts neglect to enforce this policy (ACLU, 2016). As such, based on the high rates of poverty among female probationers, they may experience problems paying their monthly supervision fees, which can range from $\$ 10$ to $\$ 135$ dollars, and subsequently become incarcerated as a result (ACLU, 2016; Chesney-Lind \& Pasko, 2013). 


\section{Racial Disparities in Probation Recidivism}

The available evidence indicates that African Americans experience recidivism at higher rates compared to other racial groups. Research specifically analyzing the racial disparities in recidivism outcomes for female probationers, however, is missing from the available literature. Nevertheless, studies including combined samples of males and females suggest that African Americans are more likely to receive technical violations and revocations than other racial groups (Steinmetz \& Henderson, 2016). For instance, African American participants experienced revocations significantly more often than other racial groups in a study of 105,220 male and female probationers (Jannetta, et al., 2014). Similarly, a study of 1,071 male and female probationers illustrated that African Americans encountered significantly more revocations compared to Whites (Steinmetz \& Henderson, 2016).

Notably absent from the existing research are explanations for the racial disparities in probation recidivism outcomes. Several possible reasons could explain these disparities. First, several studies have found that African Americans are placed on higher levels of community supervision at the start of their sentences, which increases the likelihood of receiving technical violations that result in incarcerations (Eisenberg et al., 2009; Henderson, 2006; Henderson, Daniel, Adams, \& Rembert, 2007; Rembert, Henderson, \& Pirtle, 2014; Yacus, 1998). In addition, research indicates a long-standing pattern of harsher punishments directed toward African Americans by the criminal justice system. For instance, African Americans receive longer prison sentences for drug-related offenses than other racial groups, and throughout history, have been targeted by police departments for false charges and subsequently receive more punitive punishments from 
judges following convictions (ACLU, 2016; Alexander, 2010; Mauer \& King, 2007; Zinn, 1980).

\section{Treatment Services During Probation}

The treatment services provided at community-based social service agencies are vital to the probation outcomes of offenders and frequently requirements of their sentences (Phelps, 2013). Currently, studies that examine the treatment services for female probationers are largely missing from the existing research. Nonetheless, given the impact that substance use disorders, illicit drug use, mental illness, and poverty can have on criminal justice outcomes, the ability to access treatment services may be of particular importance to female probationers (Chesney-Lind \& Pasko, 2013; Holtfreter, et al., 2004; Salisbury \& Van Voorhis, 2009; Olson, et al., 2003). This section will review the research on issues that can require treatment for female probationers and the services available to the population.

\section{Cumulative Disadvantage and Treatment Services}

As described earlier in this chapter, several of the disadvantages common to female probationers may increase the need for treatment services among the population. Specifically, the victimization histories frequent to female probationers can lead to multiple health issues, including the cognitive, emotional, and behavioral problems mentioned earlier in this chapter (Bloom, Owen, \& Covington, 2003; Chesney-Lind \& Pasko, 2013; SAMHSA, 2014). Additionally, considering the high rates of substance use disorders and illicit drug use among female probationers, treatment services could help address the possible health problems associated with these issues and therefore reduce the number of technical violations and revocations that result from positive drug screenings 
(Chesney-Lind \& Pasko, 2013; Salisbury \& Van Voorhis; Volkow et al., 2016).

Furthermore, providing services to assist female probationers in finding financial stability could improve their criminal justice outcomes given the research indicating that poverty increases recidivism and lawbreaking behavior (Holtfreter et al., 2003; Reisig et al., 2004; Steffensmeier, 1993; Steffensmeier \& Haynie, 2000).

\section{Treatment Services for Female Probationers}

Data on the treatment services provided to female probationers is largely missing from the current literature (Covington, 2008; Messina, Grella, Cartier, \& Torres, 2010; Swopes, Davis, \& Scholl, 2015; Wolff, Frueh, Shi, \& Schumann, 2012; Zlotnick, Johnson, \& Najavitis, 2009). Notwithstanding one study on a drug court intervention, research on the services provided to female probationers only includes samples of both men and women and therefore largely discounts the unique issues the population often confronts (Shaffer, Hartmen, \& Listwan, 2009). Listed below is a review of the studies on the interventions provided to probationers.

The most prominent interventions currently studied among the probation population are problem-solving courts. The two problem-solving courts of particular importance to probationers are drug courts and mental health courts, which involve providing drug or mental health treatment to non-violent offenders who qualify for the services (Goodale, Callahan, \& Steadman 2013; Shaffer, Hartman, \& Listwan, 2009). The procedures of drug and mental health courts involve probation officers, judges, prosecutors, and community agencies connecting probationers with treatment services, while the successful completion of this treatment results in offenders avoiding incarceration (Taxman et al., 2007). 
In regard to the effectiveness of drug and mental health courts, more research is available on the former than the latter. One female-only study of a drug court has been conducted thus far, and the results illustrated that participants who received the drug court intervention were rearrested significantly less often (26\%) than those who qualified for it but were placed on regular supervision (51\%) (Shaffer, Hartman, \& Listwan, 2009). However, studies with combined samples of males and females suggest that drug courts are effective at assisting probationers in avoiding incarceration, especially in comparison to control groups, although several criticisms have also been noted about the interventions (ACLU, 2016; Shaffer, Hartman, \& Listwan, 2009). For instance, the following limitations of drug courts were identified in a recent report by the ACLU (2016): (1) the only offenders accepted to the programs are those with either no criminal histories or viewed by the authorities as more likely to succeed; (2) many offenders are unable to afford the high costs of treatment; (3) the best practices for substance use treatment are rarely utilized; and (4) the participants who fail a drug tests during treatment are immediately incarcerated even though relapse is an expected part of the recovery process (ACLU, 2016).

Additionally, there are mixed results in regard to the effectiveness of mental health courts, as several studies found reductions in recidivism for those who received the intervention, whereas others found no significant impact on criminal justice outcomes (Christy, Poythress, Boothroyd, Petrila, \& Mehra, 2005; Cosden, Ellens, Schnell, \& Yamini-Diouf, 2004; Moore \& Hiday, 2006; Ferguson, Hornby, \& Zeller, 2008; Steadman, Redlich, Callahan, Robbins, \& Vesselinov, 2011). Most studies on mental health courts include primarily male samples, however, and do not take into consideration 
the victimization histories common to female offenders. As such, the impact of mental health courts on the recidivism outcomes of female probationers is largely unknown.

\section{Access to Treatment Services}

The current research indicates that probationers experience difficulties accessing treatment services. Specifically, the findings from two national studies suggest that probationers have problems accessing substance use treatment services (ACLU, 2016; Marlowe, 2003; Taxman et al., 2007). One study identified that only $50 \%$ of the probationers who needed substance use treatment actually received it, and $70 \%$ of those who accessed any services dropped out within the first three months (Marlowe, 2003). In addition, a second national study including both probationers and parolees illustrated that only $10 \%$ of the participants received any form of substance use treatment (Taxman, et al., 2007).

This shortage in treatment access is likely related to limitations in national, state, and local funding (Marlowe, 2003). Previously, states were provided with federal funding to develop Treating Accountability for Safer Communities (TASC) programs, which provided community-based case management and therapy programs to probationers, but these grants were discontinued in the late 1980 s despite evaluations indicating the services reduced drug use and recidivism (Marlowe, 2003). More recently, the Second Chance Act made federal funding available to create treatment programs for prisoners nearing their release date, but these grants are not available for community-based programs that treat probationers (U.S. Department of Justice, 2003). Therefore, states and local communities are generally left to their own devices in terms of developing 
treatment services for probationers, which is most likely the reason for the limited amount of programs available to the population (Marlowe, 2003).

\section{Race/Ethnicity and Treatment Access}

African Americans may experience additional difficulties accessing treatment services during probation sentences. A national study found that even though African Americans comprise $35 \%$ of the number of individuals arrested for drug possession offenses, they represent $21 \%$ of national drug court participants (Huddeston \& Marlowe, 2011). Evidence from the general population also indicates that African Americans confront more barriers to accessing drug and mental health treatment than other racial/ethnic groups. Specifically, Cummings, Wen, Ko, \& Druss (2014) analyzed data from 13,317 treatment facilities throughout the U.S. and found that African American participants were significantly less likely to have access to substance use treatment. The results from another study including 9,585 participants from the general population also demonstrated that African Americans had significantly lower rates of drug and mental health treatment utilization compared to Whites and Latinos (Wells, Klap, Koike, \& Sherbourne, 2001). As such, these findings provide rationale for investigating whether African American women on probation have additional difficulties accessing treatment services and if this has a subsequent impact on recidivism outcomes.

\section{Addressing Gaps in the Literature}

The existing research has generated meaningful findings in regard to the factors influencing recidivism among female probationers. So far, however, there has been little research on the impact of services for issues that affect recidivism for female probationers, (e.g., substance use disorders, illicit drug use, mental illness, and poverty). 
Specifically, only one study has examined the affect on recidivism of a substance use treatment intervention for female probationers, and none have examined the impact of mental health treatment, employment services, or financial assistance.

In addition, no research has investigated the relationship between treatment services and recidivism among a sample of female probationers who have all experienced physical and/or sexual victimization (Chesney-Lind \& Pasko, 2013). Also, no studies have examined the association between race/ethnicity, treatment access, and recidivism despite the evidence suggesting that African Americans may have more difficulty accessing treatment services and are more likely to receive revocations during their sentences (ACLU, 2016; Cummings, Wen, Ko, \& Druss, 2014; Wells, Klap, Koike, \& Sherbourne, 2001). This study will focus on addressing these gaps in the literature in order to provide additional information on the affect of treatment services on the criminal justice outcomes of female probationers. 


\section{CHAPTER III}

\section{METHODOLOGY}

This chapter includes an explanation of the methods utilized for this dissertation study. The chapter is comprised of an overview of the study, research aims, recruitment procedures, sample, data collection, strategies for data analysis, and the results from the data analyses.

\section{Overview of Study}

This study is a secondary data analysis from the Women's Health Research Study (WHRS), which was a longitudinal study of 406 women on probation or parole conducted in Louisville, Kentucky between 2010 and 2015. The WHRS was approved through the University of Louisville Institutional Review Board and a Certificate of Confidentiality was also obtained for the study. Data for the WHRS was collected in three waves. The baseline data was collected between July of 2010 and January of 2013, while the second interview occurred 12 months post-baseline (i.e., T2 follow up), and the third interview at 24 months post-baseline (i.e., T3 follow up).

\section{Research Aims}

The aim of this research is to investigate the affect of service utilization, financial assistance, income, and race/ethnicity on probation recidivism. Specifically, this study will examine whether differences in recidivism outcomes occurred at the T2 and T3 follow up interviews between the WHRS participants who received services for issues 
that were identified in the literature as impacting probation recidivism (i.e., illicit drug use, substance use disorders, mental illness, and low income) and those who did not. In addition to analyzing the affect of the services received by the WHRS probation population, the study will also investigate the impact of race/ethnicity and income on recidivism. The three objectives of the proposed study are listed below:

Objective 1: To explore the affects of drug treatment service utilization and participant race/ethnicity on the occurrences of recidivism among a sample of victimized women on probation.

Objective 2: To explore the affects of mental health treatment service utilization and participant race/ethnicity on the occurrences of recidivism among a sample of victimized women on probation.

Objective 3: To explore the affects of employment services, government financial assistance, and participant race/ethnicity on the occurrences of recidivism among a sample of victimized women on probation.

\section{Sampling and Recruitment}

The WHRS sample includes 406 women on probation or parole. However, the only participants included in the study were those on probation at the beginning of the WHRS $(n=307)$. Additional inclusion criteria for the WHRS is comprised of the following requirements: a) born female; b) speak English at a conversational level; c) on

probation in Jefferson County, Kentucky during the baseline interview; d) 18 years of age or older at the baseline interview; e) report at least one lifetime experience of physical and/or sexual victimization from a parent, caretaker, intimate partner, and/or non-intimate partner (i.e., stranger or acquaintance); and f) self-reported as having sex with either men 
or both men and women. Participants were excluded from the study if they had a cognitive or psychological issue that impaired their ability to complete the interviews.

Several methods were utilized to recruit participants for the WHRS. Specifically, in-person recruitment was conducted at local probation and parole offices; flyers advertising the study were mailed to all of the women on probation and parole in Jefferson County; flyers were distributed in the community; advertisements were placed on public access television, Craigslist, and in the local newspaper. The screenings to determine eligibility for the study were mainly conducted by telephone (89\%) but also inperson (11\%). Prior to the screenings, the potential participants were provided with information explaining the study, which included the time requirements, risks and benefits of participation, efforts made to maintain confidentiality, and who to contact with further questions about the study or the rights of research participants. The women who consented to participate in the study agreed to partake in three interviews.

Ultimately, 424 (82\%) of the 517 women screened for the study met the inclusion criteria. The most common reasons for exclusion were not being on probation or parole at the time of the study or having no history of victimization. While recruitment primarily occurred either through direct mailing $(n=170 ; 32.9 \%)$ or referrals from co-workers, probation officers, family, or friends ( $n=154 ; 32.8 \%)$, the participants also learned about the study through public flyers $(n=75 ; 14.5 \%)$, community-based agencies $(n=58$; $10.6 \%)$, contact from a recruiter $(n=48 ; 9.3 \%)$, and news advertisements $(n=12 ; 2.3 \%)$.

\section{WHRS Data Collection}

The participants were consented for the study through the University of Louisville IRB approved consent form and informed of the study's Certificate of Confidentiality. 
Several locations were utilized to conduct the interviews, including public libraries, offices, homes of participants, and other public spaces. The participants were paid $\$ 35.00$ for the baseline interview and $\$ 55.00$ for the third interview, in addition to receiving compensation for their public transportation costs to and from the interviews. The interviews were performed by trained female interviewers and on average lasted threehours.

The Audio Computer-Assisted Self-Interviewing (ACASI) computer software system was utilized to conduct the interviews, which were done on a laptop computer (Nova Research Company, 2003). Evidence suggests that ACASI increases the accuracy of interview data and reduces participant reservations in regard to the reporting of sensitive information (Newman, Jarlais, Turner, Gribble, Cooley, \& Paone, 2002; Williams, Freeman, Bowen, Zhao, Rusek, \& Signes, 2000). Additionally, password protection was utilized in order to restrict access to the computers utilized for the study and the ACASI software provides password protection and encryption of the response data.

\section{Independent Variables}

Several of the answers to questions asked to the participants at the baseline, T2, and T3 interviews were operationalized in the study as variables measuring substance use treatment utilization, mental health treatment utilization, and access to employment services and government financial resources. These variables are listed below. 


\section{Lifetime Drug and Alcohol Treatment}

To measure lifetime drug and alcohol treatment utilization, the women were asked at the baseline interview the total number of times they had participated in drug and alcohol treatment in their lives, which was used in this study as an interval level variable.

\section{Recent Drug and Alcohol Treatment Episodes}

To measure recent drug and alcohol treatment episodes over the course of the study, participants were asked at the baseline, T2, and T3 interviews on whether they had received any drug or alcohol treatment in the previous 12 months $(\mathrm{N} / \mathrm{Y})$. Based on the responses, an interval level variable was created to measure the cumulative affect of any drug or alcohol treatment services at the baseline, T2, and T3 interviews. Specifically, participants were given a score ranging from 0 to 3 depending on the number of times they reported receiving any drug and alcohol treatment over the course of the study.

\section{Recent Individual or Group Counseling for Drug or Alcohol use}

In order to measure recent individual or group counseling for drug or alcohol use over the course of the study, the women were asked at the baseline, T2, and T3 interviews about the number of times they had participated in individual or group counseling for drug or alcohol use in the previous 12 months. To assess the aggregate affect throughout the study, an interval level variable was created in which the total number of times the participants identified receiving individual or group drug or alcohol counseling sessions at the baseline, T2, and T3 interviews was added together.

\section{Recent 12-Step Program Attendance}

To measure recent 12-step program attendance over the course of the study, the women were asked at the baseline, $\mathrm{T} 2$, and $\mathrm{T} 3$ interviews the total number of times they 
had utilized a 12-step program, such as Alcoholics Anonymous or Narcotics Anonymous, in the previous 12 months. This information was subsequently combined into an interval level variable measuring cumulative participation among the participants over the course of the study.

\section{Recent Mental Health Treatment Episodes}

To measure recent mental health treatment episodes over the course of the study, each participant was asked at the baseline, $\mathrm{T} 2$, and $\mathrm{T} 3$ interviews whether they received any mental health treatment in the previous 12 months $(\mathrm{N} / \mathrm{Y})$. An interval level variable was then created in which the total number of times the participants identified as receiving any mental health treatment at baseline, $\mathrm{T} 2$, and $\mathrm{T} 3$ were added together (e.g., $0,1,2$, or 3$)$.

\section{Recent Mental Health Counseling Episodes}

In order to measure recent mental health counseling episodes over the course of the study, the total number of counseling services for psychological or emotional issues each participant identified receiving within the past 12 months at the baseline, T2, and T3 interviews were added together into an interval level variable.

\section{Recent Psychological Evaluation}

To measure recent psychological evaluations during the study, the total amount of times the women reported at the baseline, $\mathrm{T} 2$, and $\mathrm{T} 3$ interviews as having a psychological evaluation from a specialist were also added together into an interval level variable. 


\section{Recent Food, Housing, or Transportation Access}

To measure reception of food, housing, or transportation during the study, at the baseline, T2, and T3 interviews the participants were asked whether they had received any government financial assistance related to food, housing, or transportation in the previous 30 days. Each variable describing access to the resource was measured at an interval level ranging from 0 and 3.

\section{Recent Welfare, Public Assistance, or TANF Access}

In order to measure reception of welfare, public assistance, or TANF during the study, each participant was asked at the baseline, T2, and T3 interviews whether they had accessed welfare, public assistance, or TANF in the previous 30 days. This variable was measured at an interval level ranging from 0 and 3.

\section{Recent Social Security or Disability Access}

To measure reception of social security of disability during the study, each participant was asked at the baseline, T2, and T3 interviews whether they had received social security or disability in the previous 30 days. To individually measure the affect of each of the three types of financial assistance, participants were given a score designating the number of times they reported receiving each resource during the baseline, $\mathrm{T} 2$, and T3 interviews;

\section{Recent Employment Service Attendance}

To measure the employment service attendance during the study, participants were questioned at baseline, $\mathrm{T} 2$, and $\mathrm{T} 3$ interviews about the total number of times they received services in the previous 12 months. The total number of employment services 
received by the participants over the course of the study was measured as an interval level variable.

\section{Recent Social Security, Welfare, or Disability Service Attendance}

To measure social security, welfare, or disability service attendance during the study, the participants were asked the total number of times they had received a session in the past 12 months focused on helping them access SSI, welfare, disability, or other benefits. The total number of times the participants identified at the baseline, T2, and T3 interviews as receiving services to help with finding employment or accessing SSI, welfare, or disability were combined into two interval level variables measuring the total number of sessions accessed for each service over the course of the study.

\section{Race/Ethnicity}

Data on the race/ethnicity of the participant was collected during the baseline interview where the women were asked to identify their racial background. The racial groups included African American, Hispanic or Latina, White, Asian or Pacific Islanders, Native American, or Multi-racial. Since the majority of participants in the WHRS sample identified as either African American or White, the racial/ethnic groups were divided into three variables: African American; White; and a third "other" category including the remaining racial backgrounds.

\section{Income}

Income was measured during the baseline interview of the study by the participant's average monthly income over the previous year. Income was operationalized as a categorical variable with the following options: a) less than $\$ 500$; b) between $\$ 500-\$ 999$; c) between $\$ 1,000-\$ 1,999$; d) between $\$ 2,000-\$ 3,999$; e) between 
$\$ 4,000-\$ 5,999$; and f) greater than $\$ 6,000$. The different categories for measuring average monthly income were based on previous research from the WHRS study that also focused on concepts of feminist criminology related to income (see Golder et al., 2014)

\section{Control/Descriptive Variables}

Several control and descriptive variables, which are described below, were included in the study. The control variables reflected substantive factors that may affect recidivism and were therefore included in the models, whereas the descriptive variables provided assistance in describing the sample. The control variables consisted of (1) victimization histories, (2) scores on the Brief Symptom Inventory assessment, and (3) the total number of illicit drugs used in the previous 12 months. The descriptive variables were comprised of average age, employment status, educational level, and the total number of illicit drug used in the past 12 months among the participants.

\section{Victimization Histories}

During the baseline interview, each participant was asked questions regarding their physical and sexual victimization histories during childhood, from intimate partners, and from non-intimate partners. For this study, three control variables were utilized to measure the total number of times in which the participants experienced physical or sexual abuse through each type of victimization (e.g. childhood, intimate partner, and non-intimate partner). The victimization control variables are described below.

Childhood Physical or Sexual Abuse. Seven items were utilized to measure childhood physical or sexual abuse (Straus, Hambly, Boney-McCoy, \& Sugarman, 1996). During the baseline interviews, the participants were asked whether their parent or caregiver engaged in the following behaviors toward them, and if so, the total number of times: (1) 
physically hurt [them] on purpose (e.g. grabbing, slapping, burning, scalding, punching, choking, throwing around, or harshly spanking); (2) beat [them] up; (3) used a knife or gun or other weapon to get something from [them]; and (4) attacked [them] with a weapon and [they] were afraid of being injured, raped, or killed.

Also, three items were utilized to measure childhood sexual abuse. At the baseline interviews, the participants were asked the following questions in regard to whether their parent or caregiver had ever exhibited the following behaviors toward them, and if so, the total number of times it occurred: (1) forced or threatened [them] to do sexual things other than intercourse; (2) forced or threatened [them] to have sexual intercourse but it did not actually occur; (3) forced or threatened [them] to have sexual intercourse and it actually happened. The combined number of times the participants identified experiencing any of the aforementioned physical or sexual abuse events from parents or caregivers were then added together as a control variable measuring their total amount of childhood victimization.

Intimate Partner Physical or Sexual Abuse. Nine items were utilized to measure histories of experiencing physical or sexual abuse from intimate partners. During the baseline interview, each participant was asked three questions to assess their experiences with intimate partner physical abuse. The questions included whether an intimate partner had ever: (1) beat [them] up, and if so, the total number of times; (2) used a knife, gun, or other weapon to get something from [them], and if so, the total number of times; (3) attacked [them] with a weapon with the intent to injure, rape, or kill, and if so, the total number of times. The participants were also asked three questions at the baseline interview to measure their experience with sexual abuse from intimate partners. The 
questions included if an intimate partner had: (1) forced or threatened [them] to do sexual things other than sexual intercourse (i.e., forced petting or forced oral sex), and if so, the total number of times; (2) forced or threatened [them] to have sexual intercourse but it did not actually occur, and if so, the total number of times; (3) forced or threatened [them] to have sexual intercourse and it actually happened, and if so, the total number of times. The amount of times the participants identified experiencing any of the events above were added together as a variable measuring their total amount of intimate partner physical or sexual abuse.

Non-intimate Partner Physical or Sexual Abuse. At the baseline interview, the same questions listed above regarding intimate partner physical or sexual abuse were asked to the participants regarding their experiences with non-intimate partner physical or sexual abuse. The items utilized to identify instances in which the participant encountered nonintimate partner physical or sexual abuse were also utilized as a control variable that measured their total number of occurrences of non-intimate partner victimization.

\section{Brief Symptom Inventory}

Data on the Brief Symptom Inventory (BSI) was collected during the baseline interview. The scores of the participants on the BSI will be utilized in this study as a control variable to determine their psychiatric symptoms. The BSI is a 53-item self report measure that includes nine different subscales which assess the following psychiatric symptoms: somatization; obsessive compulsiveness; interpersonal sensitivity; depression; anxiety; hostility; phobic anxiety; paranoid ideation; and psychoticism (Derogatis \& Melisaratos, 1983). Evidence suggests that BSI is a valid and reliable indicator of psychopathology (Boulet, Boss, \& Marvin, 1991). To measure psychiatric symptoms this 
study utilized the total combined scores of the participants on the BSI across all nine of the subscales. The BSI was found to be highly reliable among the sample $(\alpha=.98)$.

\section{Recent Drug Use}

Data on the recent drug use of the participants was collected during the baseline interview. This variable includes the total number of different illicit drugs the women reported utilizing in the previous year. This variable has been utilized in previous WHRS studies to measure the extent of recent illicit drug use among the participants (see Golder et al., 2014). The types of substances included in this variable were: marijuana; cocaine; crack; heroin; other opiates (i.e., Percocet, OxyContin, Tylenol 2), hallucinogens, sedatives/tranquilizers (i.e., Benzos, Xanax, Seconal, Valium”); club drugs (i.e., GHB (Xyrem), Rohypnol, Ketamine (Special K), or MDMA (esstacy, and prescription drugs)

\section{Descriptive Variables}

Several descriptive variables were utilized to provide additional context pertaining to the sample. In particular, at the baseline interview data was collected regarding the age of the women as well as their employment status and highest level of education. Also, drug and alcohol use among the participants was measured at the baseline interview by their use of specific substances in the past 12 months, in the past 2 years, and during their lifetime, which included the following: marijuana; cocaine; crack; heroin; other opiates (i.e., Percocet, OxyContin, Tylenol 2), hallucinogens, sedatives/tranquilizers (i.e., Benzos, Xanax, Seconal, Valium”); club drugs (i.e., GHB (Xyrem), Rohypnol, Ketamine (Special K), or MDMA (esstacy, and prescription drugs). 


\section{Dependent Variable}

\section{Probation Recidivism}

The dependent variable for the study is probation recidivism. Based on the data available in the WHRS, probation recidivism was operationalized through a question that asked the participants at the T2 and T3 interviews whether they had been in jail or prison in the last 12 months for 24 hours or longer. Specifically, the participants who were incarcerated in the last 12 months for 24 hours or longer at either the T2 or T3 interviews were measured as a " 1 " while no reports of incarceration during that time period were measured as a " $0 . "$

\section{Analysis Strategy}

A four-part analysis plan was utilized for this study. First, a missing data analysis was conducted to examine any between-group differences between the participants who partook in all three waves of data collection and those who did not; this analysis identified any significant differences across the independent and control variables. Second, descriptive statistics for the independent and control variables were assessed, which included the frequency, mean, variance, standard deviation, and minimum and maximum values, to inform the utilization of each variable within the analyses.

Following this, bivariate comparisons were conduced across all the independent and control variables between the women who recidivated and those who did not in order to assess the person-centered differences among the women. The bivariate comparisons were conducted by performing chi-square tests for the categorical variables and $t$ tests for the interval level variables to examine the between-group differences among the women in regard to recidivism. 
Finally, three logistic regression models were conducted utilizing the backward elimination technique. Most specifically, logistic regression models were performed for each of the following models: (1) the substance use treatment variables, race/ethnicity, income, and the control variables; (2) the mental health treatment variables, race/ethnicity, income, and the control variables; and (3) the financial assistance and employment services variables, race, income, and the control variables. Logistic regression is a statistical procedure that determines the probability an event will occur based on a pattern of responses to a given number of questions (Meyers, Gamst, \& Guarino, 2013; Tabachnick \& Fidell, 2013). The goal of logistic regression is to generate a model in the form of a linear equation that indicates the best weighted linear combination of independent variables to predict the dependent variable (Meyers, Gamst, \& Guarino, 2013; Tabachnick \& Fidell, 2013). Backward elimination is a model building technique in which each predictor variables that does not produce a significant reduction in $R^{2}$ is eliminated from the model (Golder \& Logan, 2011; Tachachnick \& Fidell, 2001). The backward elimination technique is a common model building technique in the social sciences and therefore was utilized for this study instead of standard regression in order to generate a greater understanding of the association between substance use treatment utilization, mental health treatment utilization, financial assistance, race/ethnicity, poverty, victimization, substance use, and recidivism (Golder \& Logan, 2011; Tabachnick \& Fidell, 2001). The SPSS version 23 was utilized for all of the analyses and the statistical tests were performed at a 0.05 level of significance. 


\section{Assumptions of Logistic Regression}

Prior to running the analyses, each of the three models were checked to examine whether or not they met the assumptions of logistic regression. Following this, it was determined that each of the three regression models met the assumptions of logistic regression, which include absence of multicollinearity, independence of errors, lack of strongly influential outliers, and having an adequate number of cases per each independent variable. As such, it was decided that moving forward with the regression analysis was possible. 


\section{CHAPTER IV}

\section{RESULTS}

\section{Missing Data Analysis}

Since data for the present research was taken from a longitudinal study, some participants are missing from the $\mathrm{T} 2$ and $\mathrm{T} 3$ waves of data collection. Therefore, an analysis was conducted for all the independent variables to identify any between-group differences between the women who completed all of the interviews and those who were missing at $\mathrm{T} 2$ and/or T3. Overall, 307 female probationers participated in the WHRS, 262 of whom completed the $\mathrm{T} 2$ interview and 247 the $\mathrm{T} 2$ and $\mathrm{T} 3$ interviews. The percentage of cases missing after the $\mathrm{T} 1$ interview was $15 \%$ of the total sample, while $20 \%$ of the total sample was missing after the $\mathrm{T} 2$ interview. The results of the bivariate comparisons between the missing and non-missing cases are listed in Tables 1, 2, 3, and 4. While the majority of the variables did not have an affect on whether or not the women completed the T2 and T3 interviews, statistical significance was found for race/ethnicity, low income, participation in 12-step meetings at baseline, and receiving any mental health treatment at baseline.

The findings identified that White participants were more likely to have missing data at T2 and both T2 and T3. Additionally, women with lower income had a greater likelihood of missing both the T2 and T3 interviews. Also, women who participated in fewer 12-step meetings at baseline were more likely to miss the $\mathrm{T} 3$ interview than those 
with more participation in 12-step meetings. Furthermore, women who received any mental health treatment at baseline were less likely to miss $\mathrm{T} 2$ and $\mathrm{T} 3$ interviews while women with any mental health treatment at $\mathrm{T} 3 \mathrm{had}$ a greater likelihood of partaking in the $\mathrm{T} 2$ interview.

Based on the missing cases analysis, 60 women participated in the baseline WHRS interview and not the T2 or T3 follow-ups. The decision was therefore made to only include in the bivariate and regression analyses cases with complete data $(n=247)$, thus allowing for an examination of the affect the independent variables had on recidivism over the entire study. Although the reasons are unknown for why the 60 women did not participate in the $\mathrm{T} 2$ and $\mathrm{T} 3$ waves, several of the findings from the missing cases analyses could have an impact on the objectives of this study. For instance, the bivariate missing cases analyses identified that participants were more likely to miss the T2 or T3 interviews if they had lower average monthly incomes, which was identified in previous research as increasing recidivism (Holtfreter, Reisig, \& Morash, 2004; Salisbury \& Van Voorhis, 2009). If applicable, the interpretation of the results will therefore take into consideration whether the independent variables that affected participation in $\mathrm{T} 2$ and $\mathrm{T} 3$ waves of data collection also affected recidivism outcomes. 
Table 1.

Comparison of Missing and Non-Missing Race/Ethnicity and Income Variables ${ }^{\mathrm{a}, \mathrm{b}}$

\begin{tabular}{|c|c|c|c|c|}
\hline Variables & $\begin{array}{c}\text { Complete Data } \\
\text { (Mean or \%) } \\
n=246\end{array}$ & $\begin{array}{c}\text { Missing at T2 } \\
\text { (Mean or \%) } \\
n=45\end{array}$ & $\begin{array}{c}\text { Missing at T3 } \\
\text { (Mean or \%) } \\
n=34\end{array}$ & $\begin{array}{c}\text { Missing at T2 } \\
\text { and T3 } \\
\text { (Mean or \%) } \\
n=22\end{array}$ \\
\hline $\begin{array}{c}\text { Race/Ethnicity } \\
\text { African } \\
\text { American }\end{array}$ & $48.0 \%$ & $22.2 \%$ & $26.5 \%$ & $9.1 \%$ \\
\hline White & $44.0 \%$ & $66.7 \% *$ & $61.8 \%$ & $72.7 \% *$ \\
\hline Other & $8.0 \%$ & $11.1 \%$ & $11.8 \%$ & $18.2 \%$ \\
\hline $\begin{array}{l}\text { Income } \\
\quad>\$ 500\end{array}$ & $82.3 \%$ & $52.3 \%$ & $47.1 \%$ & $50.0 \% *$ \\
\hline$\$ 500-999$ & $83.0 \%$ & $25.0 \%$ & $32.4 \%$ & $22.7 \%$ \\
\hline $\begin{array}{l}\$ 1,000- \\
1,999\end{array}$ & $76.9 \%$ & $18.2 \%$ & $17.6 \%$ & $22.7 \%$ \\
\hline $\begin{array}{l}\$ 2,000- \\
3,999\end{array}$ & $75 \%$ & $2.3 \%$ & $0.0 \%$ & $0.0 \%$ \\
\hline $\begin{array}{l}\$ 4,000- \\
5,999\end{array}$ & $0.0 \%$ & $2.3 \%$ & $2.9 \%$ & $4.5 \%$ \\
\hline
\end{tabular}

${ }^{a} t$-tests were conducted for interval level data and chi-square tests were conducted for categorical level data.

${ }^{b}$ The comparisons in these analyses were between women who had data at all three points of the study, those who had data at only T1 and T2, and those who had data at only T1.

$* \mathrm{p} \leq .05$ 
Table 2.

Comparison of Missing and Non-Missing Substance Use Treatment Variables ${ }^{\mathrm{a}, \mathrm{b}}$

\begin{tabular}{lcccc}
\hline Variable & $\begin{array}{c}\text { Complete Data } \\
(\text { Mean or \%) } \\
n=250\end{array}$ & $\begin{array}{c}\text { Missing at T2 } \\
(\text { Mean or } \% n) \\
n=45\end{array}$ & $\begin{array}{c}\text { Missing at T3 } \\
(\text { Mean or \%) } \\
n=34\end{array}$ & $\begin{array}{c}\text { Missing at T2 } \\
\text { and T3 (Mean } \\
\text { or \%) } \\
n=22\end{array}$ \\
\hline Total Drug or & 3.34 & 6.47 & 4.39 & 6.05
\end{tabular}

Alcohol

Treatment in

Lifetime

$\begin{array}{lllll}\text { Any Drug or } & 38.4 \% & 37.2 \% & 11.9 \% & 38.1 \% \\ \text { Alcohol } & & & \\ \text { Treatment in } & & & \\ \text { Past } 12 \mathrm{~m} \text { at } & & & \\ \text { Baseline } & & & \end{array}$

Any Drug or

$37.5 \%$

$38.5 \%$

Alcohol

Treatment in

Past $12 \mathrm{~m}$ at T2

Any Drug or

Alcohol

$33.6 \%$

$26.1 \%$

$100 \%$

Treatment in

Past $12 \mathrm{~m}$ at T3

Counseling

22.02

19.30

10.63

16.70

Sessions for

Drug or

Alcohol Use in

Past $12 \mathrm{~m}$ at

Baseline

Counseling

11.37

5.61

Sessions for

Drug or

Alcohol Use in

Past $12 \mathrm{~m}$ at T2

Counseling

9.97

14.56

5.00

Sessions for

Drug or

Alcohol Use in

Past $12 \mathrm{~m}$ at T3 
$\begin{array}{lllll}\text { AA or NA } & 36.60 & 38.18 & 15.41 * & 23.45\end{array}$

Sessions in Past

$12 \mathrm{~m}$ at Baseline

AA or NA

Sessions in Past

$12 \mathrm{~m}$ at $\mathrm{T} 2$
27.05

17.91

\author{
(
}

(n)

AA or NA

Sessions in Past

$12 \mathrm{~m}$ at $\mathrm{T} 3$
${ }^{\mathrm{a}} t$-tests were conducted for interval level data and chi-square tests were conducted for categorical level data.

${ }^{b}$ The comparisons in these analyses were between women who had data at all three points of the study, those who had data at only T1 and T2, and those who had data at only T1.

$* \mathrm{p} \leq .05$ 
Table 3.

Comparison of Missing and Non-Missing Mental Health Treatment Variables ${ }^{\mathrm{a}, \mathrm{b}}$

\begin{tabular}{|c|c|c|c|c|}
\hline Variable & $\begin{array}{c}\text { Complete Data } \\
\text { (Mean or \%) } \\
n=250\end{array}$ & $\begin{array}{c}\text { Missing at T2 } \\
\text { (Mean or \%) } \\
n=45\end{array}$ & $\begin{array}{c}\text { Missing at T3 } \\
\text { (Mean or \%) } \\
n=34\end{array}$ & $\begin{array}{c}\text { Missing at T2 } \\
\text { and T3 } \\
\text { (Mean or \%) } \\
n=22\end{array}$ \\
\hline $\begin{array}{l}\text { Any Mental } \\
\text { Health } \\
\text { Treatment in } \\
\text { Past } 12 \mathrm{~m} \text { at } \\
\text { Baseline }\end{array}$ & $76.1 \% *$ & $18.7 \% *$ & $15.7 \% *$ & $10.4 \%$ \\
\hline $\begin{array}{l}\text { Any Mental } \\
\text { Health } \\
\text { Treatment in } \\
\text { Past } 12 \mathrm{~m} \text { at } \mathrm{T} 2\end{array}$ & $94.7 \%$ & - & $5.3 \%$ & - \\
\hline $\begin{array}{l}\text { Any Mental } \\
\text { Health } \\
\text { Treatment in } \\
\text { Past } 12 \mathrm{~m} \text { at } \mathrm{T} 3\end{array}$ & $95.5 \%$ & $13.6 \% *$ & $0.3 \%$ & \\
\hline $\begin{array}{l}\text { Mental Health } \\
\text { Counseling } \\
\text { Sessions in Past } \\
12 \mathrm{~m} \text { at Baseline }\end{array}$ & 7.71 & 8.10 & 5.58 & 4.62 \\
\hline $\begin{array}{l}\text { Mental Health } \\
\text { Counseling } \\
\text { Sessions in Past } \\
12 \mathrm{~m} \text { at T2 }\end{array}$ & 9.05 & - & 3.40 & - \\
\hline $\begin{array}{l}\text { Mental Health } \\
\text { Counseling } \\
\text { Sessions in Past } \\
12 \mathrm{~m} \text { at T3 }\end{array}$ & 8.95 & 44.66 & 2.00 & - \\
\hline $\begin{array}{l}\text { Psych. Evals. in } \\
\text { Past } 12 \mathrm{~m} \text { at } \\
\text { Baseline }\end{array}$ & 7.36 & 8.72 & 5.00 & 5.64 \\
\hline $\begin{array}{l}\text { Psych. Evals. in } \\
\text { Past } 12 \mathrm{~m} \text { at T2 }\end{array}$ & 3.55 & - & 3.00 & 3.52 \\
\hline $\begin{array}{l}\text { Psych. Evals in } \\
\text { Past } 12 \mathrm{~m} \text { at T3 }\end{array}$ & 4.28 & 27.66 & 2.00 & 5.06 \\
\hline
\end{tabular}


${ }^{a} t$-tests were conducted for interval level data and chi-square tests were conducted for categorical level data.

${ }^{b}$ The comparisons in these analyses were between women who had data at all three points of the study, those who had data at only T1 and T2, and those who had data at only T1.

$* \mathrm{p} \leq .05$ 
Table 4.

Comparison of Missing and Non-Missing Financial Resources Services Variables ${ }^{\mathrm{a}, \mathrm{b}}$

\begin{tabular}{|c|c|c|c|c|}
\hline Variable & $\begin{array}{c}\text { Complete Data } \\
\text { (Mean or \%) } \\
n=250\end{array}$ & $\begin{array}{c}\text { Missing at T2 } \\
\text { (Mean or \%) } \\
n=45\end{array}$ & $\begin{array}{c}\text { Missing at T3 } \\
\text { (Mean or \%) } \\
n=34\end{array}$ & $\begin{array}{c}\text { Missing at } \mathrm{T} 2 \text { and } \\
\text { T3 } \\
\text { (Mean or \%) } \\
n=22\end{array}$ \\
\hline $\begin{array}{l}\text { Employment } \\
\text { Sessions at } \\
\text { Baseline }\end{array}$ & 0.79 & 0.80 & 0.68 & 0.64 \\
\hline $\begin{array}{l}\text { Sessions to } \\
\text { Access } \\
\text { Employment } \\
\text { at T2 }\end{array}$ & 0.42 & 0.00 & 0.44 & .54 \\
\hline $\begin{array}{l}\text { Sessions to } \\
\text { Access } \\
\text { Employment } \\
\text { at T3 }\end{array}$ & 0.68 & 0.65 & - & - \\
\hline $\begin{array}{l}\text { Sessions to } \\
\text { Access } \\
\text { Welfare at } \\
\text { Baseline }\end{array}$ & 1.03 & 0.95 & 0.76 & 0.77 \\
\hline $\begin{array}{l}\text { Sessions to } \\
\text { Access SS, } \\
\text { Welfare, or } \\
\text { Disability at } \\
\text { T2 }\end{array}$ & 0.96 & 1.00 & 0.58 & 2.00 \\
\hline $\begin{array}{l}\text { Sessions to } \\
\text { Access } \\
\text { Welfare at } \\
\end{array}$ & 1.07 & 0.32 & - & - \\
\hline
\end{tabular}

$\begin{array}{lllll}\text { Any Aid for } & 70.4 \% & 66.7 \% & 76.5 \% & 68.2 \%\end{array}$

Food,

Housing, or

Trans. Last

in $12 \mathrm{~m}$ at $\mathrm{T} 1$

Any Aid for

$64.1 \%$

$5.4 \%$

$64.1 \%$

Food,

Housing, or

Trans. Aid 
in last $12 \mathrm{~m}$

at $\mathrm{T} 2$

Any Aid for

$64.5 \%$

$59.1 \%$

Food,

Housing, or

Trans. Gov.

Aid in last

$12 \mathrm{~m}$ at $\mathrm{T} 3$

SSI, SSDI,

$22.0 \%$

$20.5 \%$

$23.5 \%$

$18.2 \%$

or Worker's

Comp. in

Past 30

Days at $\mathrm{T} 1$

SSI, SSDI,

$25.0 \%$

$23.1 \%$

or Worker's

Comp. in

Past 30

Days at T2

SSI, SSDI,

or Worker's

Comp. in

Past 30

Days at T3

Welfare or

$25.6 \%$

$15.9 \%$

$11.8 \%$

$13.6 \%$

TANF in

Past 30

Days at $\mathrm{T} 1$

Welfare or

$21.8 \%$

$1.8 \%$

$23.1 \%$

$100 \%$

TANF in

Past 30

Days at T2

Received

$25.2 \%$

$17.4 \%$

Welfare or

TANF in

Past 30

Days at T3

\footnotetext{
${ }^{\mathrm{a}} t$-tests were conducted for interval level data and chi-square tests were conducted for categorical level data.
} 
${ }^{b}$ The comparisons in these analyses were between women who had data at all three points of the study, those who had data at only T1 and T2, and those who had data at only T1.

$* \mathrm{p} \leq .05$ 


\section{Descriptive Findings}

\section{Sociodemographic Variables}

Results of the sociodemographic variables are listed in Table 5. The average age of the participants was 36.96 years old. Regarding their racial background, most of the women were either White (44.1\%) or African American (48.2\%). At the baseline interview, over half of the participants (53\%) reported an average monthly income of less than $\$ 500,33.6 \%$ had an average monthly income between $\$ 500-\$ 999$, and $12 \%$ between $\$ 1,000$ and $\$ 2,000$. A fewer number of the women identified an average monthly income between $\$ 2,000$ and $\$ 3,999(1.2 \%)$. The most common level of educational attainment was a high school degree or GED equivalent (35.2\%), while nearly one-third of the women $(31.0 \%)$ either graduated from or attended college, and one-quarter $(25.1 \%)$ reported less than a high school degree, and a smaller number (3.6\%) attended graduate school or had a graduate degree. In terms of employment status, over one-half of the participants (51.0\%) were unemployed and nearly one-fifth (19.0\%) were disabled and non-working; the remaining women reported working full $(14.2 \%)$ or part-time $(15.8 \%)$.

\section{Drug and Alcohol Use}

Data on the past and current drug and alcohol use among the women is listed in Table 6. Past and current drug and alcohol use was common, as $93.1 \%$ of the participants identified lifetime illicit drug use, $66.1 \%$ within the past two years, and $53.7 \%$ in the previous 12 months. Alcohol use to intoxication was also frequent, as $69.4 \%$ of the women reported at least one lifetime instance of alcohol use to intoxication, $33.7 \%$ in the past two years, and $23.3 \%$ in the previous 12 months. Lifetime use of several illicit drugs was common among the participants, including marijuana $(87.6 \%)$, cocaine $(68.5 \%)$, 
crack (48.1\%), other opiates (43.3\%) and sedatives $(42.0 \%)$, while a fewer but still substantial number of women reported lifetime use of methamphetamine $(28.3 \%)$, hallucinogens $(27.9 \%)$, club drugs $(24.5 \%)$, and heroin $(18.5 \%)$ use. In regard to illicit drug use in the previous two years, a greater number of the women reported use of marijuana $(45.6 \%)$, other opiates $(27.5 \%)$, cocaine $(26.7 \%)$, sedatives/tranquilizers/barbiturates $(25.2 \%)$, and crack cocaine $(21.5 \%)$, while a few number identified using methamphetamine $(10.9 \%)$, heroin $(9.4 \%)$, club drugs $(6.2 \%)$, and hallucinogens $(2.0 \%)$. In terms of illicit drug use within the previous year, the most frequent substances used by the women were marijuana $(33.7 \%)$, other opiates $(23.0 \%)$, cocaine $(21.2 \%)$, sedatives/tranquilizers/barbiturates $(20.2 \%)$, crack cocaine $(17.3 \%)$; a fewer number of the participants identified past year use of heroin $(7.8 \%)$, methamphetamine (7.4\%), club drugs $(2.7 \%)$, and hallucinogens $(0.7 \%)$.

\section{Victimization}

Data on the victimization histories of the participants is included in Table 7. Experiences with physical or sexual abuse, either during childhood or from intimate or non-intimate partners, were common among the participants. Specifically, $64.3 \%$ experienced childhood physical abuse from a parent or caregiver, $38.7 \%$ encountered childhood sexual abuse from a parent or caregiver, and 69.5\% reported having either childhood physical or sexual abuse histories from a parent or caregiver. In regard to intimate partner violence, $89.7 \%$ of the women reported histories of physical abuse, $53.2 \%$ had sexual abuse histories, and $90.4 \%$ experienced either physical or sexual abuse. Additionally, non-intimate partner physical abuse was experienced by $56.7 \%$ of the participants, while $59.6 \%$ reported histories of sexual abuse and $72.2 \%$ either physical or 
sexual abuse. In regard to the mean number of times in which the participants experienced each type of victimization, the women encountered childhood physical or sexual abuse from a parent or caregiver an average of 2.09 times in their lifetime.

Pertaining to intimate partner abuse, the participants experienced physical or sexual abuse in the lifetime an average of 3.78 times. In terms of non-intimate partner physical or sexual abuse abuse, the participants reported experiencing it an average of 2.65 times in their lifetime. 
Table 5.

Sociodemographic Variables $(n=247)$

\begin{tabular}{|c|c|c|}
\hline Variables & Frequency & Percentage or Mean \\
\hline \multicolumn{3}{|l|}{ Race/Ethnicity } \\
\hline African American & 119 & $48.2 \%$ \\
\hline White & 109 & $44.1 \%$ \\
\hline Other & 19 & $7.7 \%$ \\
\hline \multicolumn{3}{|l|}{ Average Monthly Income } \\
\hline Less than $\$ 500$ & 131 & $53 \%$ \\
\hline$\$ 500-\$ 999$ & 83 & $33.6 \%$ \\
\hline$\$ 1,000-\$ 1,999$ & 30 & $12.1 \%$ \\
\hline$\$ 2,000-\$ 3,999$ & 3 & $1.2 \%$ \\
\hline Age & & 36.96 \\
\hline \multicolumn{3}{|l|}{ Highest Education Level } \\
\hline Less than High School & 62 & $\begin{array}{l}25.1 \% \\
35.2 \%\end{array}$ \\
\hline GED/High School & 87 & \\
\hline Some College/College & 80 & $32.3 \%$ \\
\hline Some Graduate/Graduate & 9 & $3.6 \%$ \\
\hline \multicolumn{3}{|l|}{ Employment Status } \\
\hline Unemployed & 135 & $51.0 \%$ \\
\hline Working Full-time & 35 & $14.2 \%$ \\
\hline Working Part-time & 39 & $15.8 \%$ \\
\hline Disabled & 47 & $19.0 \%$ \\
\hline
\end{tabular}


Table 6.

Substance Use Among the Participants ( $n=247)$

\begin{tabular}{lccc}
\hline Substance & Lifetime & $\begin{array}{c}\text { Used in past } \\
\text { two years }\end{array}$ & $\begin{array}{c}\text { Used in past } \\
12 \text { month }\end{array}$ \\
\hline $\begin{array}{l}\text { Any illicit drug } \\
\text { use }\end{array}$ & $93.1 \%$ & $66.1 \%$ & $53.7 \%$ \\
$\begin{array}{l}\text { Alcohol to } \\
\text { intoxication }\end{array}$ & $69.4 \%$ & $33.7 \%$ & $23.3 \%$ \\
Marijuana & $87.6 \%$ & $45.6 \%$ & $33.7 \%$ \\
Cocaine & $68.5 \%$ & $26.7 \%$ & $21.2 \%$ \\
Crack cocaine & $48.1 \%$ & $21.5 \%$ & $17.3 \%$ \\
Heroin & $18.5 \%$ & $9.4 \%$ & $7.8 \%$ \\
Other opiates & $43.3 \%$ & $27.5 \%$ & $23.0 \%$ \\
Methamphetamine & $28.3 \%$ & $10.9 \%$ & $7.4 \%$ \\
Club drugs & $24.5 \%$ & $6.2 \%$ & $2.7 \%$ \\
$\begin{array}{l}\text { Sedatives, } \\
\text { Tranquilizers, or }\end{array}$ & $42.0 \%$ & $25.2 \%$ & $20.2 \%$ \\
Barbiturates & & & \\
Hallucinogens & $27.9 \%$ & $2.0 \%$ & \\
\hline
\end{tabular}


Table 7.

Victimization Histories $(n=247)$

\begin{tabular}{lcc}
\hline Experience & Percentage & $\begin{array}{c}\text { Mean Total Number of } \\
\text { Times }\end{array}$ \\
$\begin{array}{l}\text { Childhood Victimization } \\
\text { Physical or Sexual Abuse }\end{array}$ & $69.5 \%$ & 2.09 \\
Physical Abuse & $64.3 \%$ & .63 \\
Sexual Abuse & $38.7 \%$ & .36 \\
Intimate Partner Violence \\
Physical or Sexual Abuse \\
$\begin{array}{l}\text { Physical Abuse } \\
\text { Sexual Abuse }\end{array}$ & $90.4 \%$ & 3.78 \\
Non-intimate Partner Violence & $89.7 \%$ & .90 \\
Physical or Sexual Abuse & $53.2 \%$ & .55 \\
Physical Abuse & $72.2 \%$ & .60 \\
Sexual Abuse & $56.7 \%$ & .62 \\
\hline
\end{tabular}




\section{Bivariate Results}

Table 8 includes the results from the bivariate comparisons of the affect that each independent variable and control variable had on recidivism. The findings demonstrate that several of the variables impacted the recidivism outcomes among the participants. Specifically, the women who reported receiving social security or disability in the previous 30 days at more points during the study were significantly less likely to recidivate, $t(247)=3.40, p=.01$. Also, the participants who identified receiving any drug of alcohol treatment more frequently over the course of the study recidivated significantly more often, $t(247)=-3.698, p=.01$. Additionally, the women who reported receiving more psychological evaluations in the previous 12 months over the course of the study were significantly less likely to recidivate, $t(245)=2.378, \mathrm{p}=.018$. Furthermore, the participants who reported higher numbers of total illicit drugs used in the previous year at the baseline interview were significantly more likely to recidivate, $t$ $(247)=-2.127, p=.036$. The results from the rest of the bivariate comparisons indicated none of the other variables significantly affected recidivism outcomes for the participants. 
Table 8.

Differences Among Women Who Recidivated and Those Who Did Not ${ }^{a}$

\begin{tabular}{lcccc}
\hline $\begin{array}{l}\text { Independent/ } \\
\text { Control Variables }\end{array}$ & $\begin{array}{c}\text { Total Sample } \\
\text { (Mean/ } \\
\text { Percentage) } \\
n=247\end{array}$ & $\begin{array}{c}\text { Women Who } \\
\text { Recidivated } \\
\text { (Mean/ } \\
\text { Percentage) } \\
n=68\end{array}$ & $\begin{array}{c}\text { Women Who Did } \\
\text { Not Recidivate } \\
\text { (Mean/ } \\
\text { Percentage) } \\
n=179\end{array}$ & $\begin{array}{c}\text { Chi- } \\
\text { square/ } \\
\text { T }\end{array}$ \\
\hline $\begin{array}{l}\text { Total Lifetime } \\
\text { Drug Treatment }\end{array}$ & 3.36 & 3.62 & 3.26 & -.223 \\
Recent Drug or & 1.11 & 1.53 & & .94 \\
A & & & $-3.698^{*}$
\end{tabular}

Alcohol

Treatment

Episodes

Recent Drug and

63.00

35.59

$-1.92$

Alcohol

Treatment

Recent 12-Step

81.20

92.71

76.83

$-.731$

Attendance

Recent Mental

1.09

1.31

1.01

$-1.837$

Health Treatment

10.52

7.63

11.62

$-1.919$

Health

Counseling

Sessions

Recent

5.55

3.03

6.50

$2.378^{*}$

Psychological

Evaluations

Recent Social

2.93

2.49

3.11

.910

Security, Welfare,

or Disability

Sessions

Recent

1.42

1.94

1.22

$-1.048$

Employment

Services

Recent Food, 
Housing

Recent Social

.74

.38

.87

$3.40 *$

Security or

Disability Access

Recess Welfare

Access

Race/Ethnicity

African

American

$48.2 \%$

$39.7 \%$

$51.4 \%$

White

$44.1 \%$

$51.5 \%$

$41.3 \%$

Other

$7.7 \%$

$8.8 \%$

$7.3 \%$

Average Monthly .146

Income

Less than $\$ 500$

$53 \%$

$64.7 \%$

$48.6 \%$

$\$ 500-\$ 999$

$33.6 \%$

$25.0 \%$

$36.9 \%$

$\$ 1,000-\$ 1,999$

$12.1 \%$

$8.8 \%$

$13.4 \%$

$\$ 2,000-\$ 3,999$

$1.2 \%$

$1.2 \%$

$1.1 \%$

Total Number of

1.43

1.86

1.26

$.036^{*}$

Illicit Drugs Used

in Past Year

BSI

1.20

1.33

1.15

$-1.400$

Total Childhood

2.09

2.14

2.06

$-.296$

Victimization

Total IPV

3.78

3.85

3.75

$-.302$

Total NIPV

2.64

2.46

2.72

1.506

${ }^{a}$ Between group differences among women who recidivated and those that did not were assessed utilizing t-tests for interval level data and chi-square tests for categorical level data.

$* p \leq .05$ 


\section{Logistic Regression Results}

\section{Objective 1: Substance Use Treatment, Race/Ethnicity, and Income Model}

In order to examine their affect on the dependent variable (i.e., recidivism), the following independent variables were entered into the substance use treatment, race/ethnicity, and income regression model: (1) the number of times each participant received drug or alcohol treatment in their lifetime; (2) the total number of times each woman identified receiving any drug or alcohol treatment in the previous 12 months during the baseline, T2, and T3 interviews; (3) the combined number of drug or alcohol counseling each participant reported receiving in the past 12 months at the baseline, T2, and T3 interviews; (4) the combined number of times the participants identified participating in AA, NA, or another 12-step program in the past 12 months at the baseline, T2, and T3 interviews; (5) participant race/ethnicity; (6) the average monthly income of the participant over the previous year at baseline. In addition, the following control variables were entered into the model: (1) scores on the Brief Symptom Inventory; (2) the total number of times the participants reported experiencing childhood physical or sexual abuse from a parent or caregiver at baseline; (3) the total number of times the women identified experiencing intimate partner physical or sexual abuse in their lifetime at baseline; (4) the total number of times the participants reported experiencing non-intimate partner physical or sexual abuse in their lifetime at baseline; and (5) the total number of illicit drugs the women identified using in the previous 12 months at baseline.

The results from the final model for the substance use, race/ethnicity, and income model are listed in Table 9. The final model accounted for $9 \%$ of the variance in 
recidivism (Nagelkerke $R^{2}=.09$ ). The final model was statistically reliable compared to the constant-only model, $\chi^{2}(2, N=247)=15.830, p \leq 01$, thus indicating the predictor variables can reliably classify the women who recidivated (Tabachnick \& Fidell, 2001). Two variables were retained in the final model: the total number of times the participants identified receiving any drug or alcohol treatment in the past 12 months across any of the three interviews and the average monthly income of the women at baseline. Only the former variable reached the conventional level of significance; for each point during the study in which the participants identified receiving any drug or alcohol treatment in the previous 12 months was associated with a $50 \%$ increased in the odds of recidivating, $(B=$ .435 , Wald $\chi^{2}=11.801, p=.001, \exp (B)=1.54$.).

\section{Objective 2: Mental Health Treatment, Race/Ethnicity, and Income Model}

In order to assess their affect on the dependent variable (i.e., recidivism), the following independent variables were entered into the mental health treatment, race/ethnicity, and income model: (1) the total number of times the participants identified receiving any mental health treatment in the previous 12 months at the baseline, $\mathrm{T} 2$, and T3 interviews; (2) the combined number of mental health counseling sessions the women reported receiving in the past 12 months at the baseline, T2, and T3 interviews; and (3) the cumulative number of times the participants identified having a psychological evaluation in the past 12 months at the baseline, T2, and T3 interviews; (4) participant race/ethnicity; and (5) average monthly income of the women in the previous 12 months at the baseline interview.

Several control variables were also entered into the model: (1) the participant score on the Brief Symptom Inventory; (2) the total number of times the participants 
identified experiencing childhood physical or sexual abuse from a parent or caregiver in their lifetime at the baseline interview; (3) the total number of times the women reported experiencing intimate partner physical or sexual abuse in their lifetime during the baseline interview; (4) the total number of times the participants reported experiencing non-intimate partner physical or sexual abuse in their lifetime at the baseline interview; and (5) the total number of illicit drugs the women reported using in the previous 12 months at the baseline interview.

The results from the final model of the mental health treatment, race/ethnicity, and income model are listed in Table 5. The final model accounted for $12 \%$ of the variance in recidivism (Nagelkerke $R^{2}=.12$ ). The final model was statistically reliable compared with the constant-only model, $\chi^{2}(4, N=247)=102.001, p \leq 01$, which indicates the predictor variables can reliably identify the women who recidivated (Tabachnick \& Fidell, 2001). Four variables were retained in the final model predicting recidivism, including the total number of times receiving any mental health treatment in the past 12 months across the study, the total number of mental health counseling received in previous 12 months throughout the study, average monthly income at baseline, and the total number of illicit drugs used in the past 12 months at baseline. Three of the variables retained in the final model were statistically significant predictors of recidivism. Specifically, each point during the study in which the participants identified receiving any mental health treatment in the previous 12 months was associated with a $60 \%$ increase in the odds of recidivating, $B=.452$, Wald $\chi^{2}=7.187, p=.007$, $\exp (B)=1.60$. In addition, each additional illicit drug utilized by the participants in the previous 12 months at baseline was associated with a $20 \%$ increase in the odds of 
recidivating, $B=.181$, Wald $\chi^{2}=5.334, p=.021, \exp (B)=1.20$. Also, having lower average monthly incomes at the baseline interview was associated with a $36 \%$ increase in the odds of recidivism, $B=-.445$, Wald $\chi^{2}=3.975, p=.046$, $\exp (B)=.641$.

\section{Objective 3: Employment Services, Financial Assistance, Race/Ethnicity, and}

\section{Income Model}

In order to measure their affect on the dependent variable (i.e., recidivism), the following independent variables were entered into the employment services, financial assistance, race/ethnicity, and income model: (1) the total number of times the participants reported receiving a session to assist with accessing social security, welfare, or disability in the past 12 months at the baseline, T2, and T3 interviews; (2) the combined number of times the participant identified receiving services to assist with finding employment in the previous 12 months at the baseline, T2, and T3 interviews; (3) the cumulative number of times the participant reported receiving government assistance for food, transportation, or housing in the previous 30 days at the baseline, T2, and T3 interviews; (4) the total number of times at the baseline, T2, and T3 interviews in which the women identified receiving social security or disability in the last 30 days; and (5) the combined number of times the participants reported receiving welfare in the previous 30 days at the baseline, T2, and T3 interviews; (6) participant race/ethnicity; and (7) average monthly income of the women in the previous 12 months at the baseline interview.

Also, the following control variables were entered into the model: (1) scores on the Brief Symptom Inventory; (2) the total number of times in which the women reported experiencing childhood physical or sexual abuse from a parent or caregiver in their

lifetime at baseline; (3) the total number of times the participants identified experiencing 
intimate partner physical or sexual abuse in their lifetime at baseline; (4) the total number of times the women reported experiencing non-intimate partner physical or sexual abuse in their lifetime at baseline; and (5) the total number of illicit drugs the participants identified using in the past 12 months at baseline.

The results from the final model for the financial assistance, employment services, race/ethnicity, and income model are listed in Table 5. The final model accounted for $8 \%$ of the variance in recidivism (Nagelkerke $R^{2}=.08$ ). Two variables were retained in the final model, the number of times the participants identified receiving social security or disability in the past 30 days at baseline, $\mathrm{T} 2$, and $\mathrm{T} 3$ and the total number of illicit drugs the women reported using in the past 12 months at baseline. Only the variable reflecting the number of times the women reported receiving social security or disability reached the conventional level of significance; each point during the study in which the participants identified receiving social security or disability in the previous 12 months was associated with a $35 \%$ decrease in the odds of recidivating, $B=-.421$, Wald $\chi^{2}=7.488, p=.006, \exp (B)=.656$. 
Table 9.

Final Logistic Regression Models Predicting Recidivism

\begin{tabular}{|c|c|c|c|c|}
\hline Variables & Beta & Standard Error & Odds Ratio & $95 \% \mathrm{CI}$ \\
\hline $\begin{array}{l}\text { Substance Use } \\
\text { Treatment } \\
\text { Model }\end{array}$ & & & & \\
\hline $\begin{array}{l}\text { Any Drug } \\
\text { Treatment }\end{array}$ & $.425^{*}$ & .127 & 1.545 & {$[1.205,1.979]$} \\
\hline $\begin{array}{l}\text { Average } \\
\text { Monthly } \\
\text { Income }\end{array}$ & -.359 & .213 & 699 & {$[.460,1.061]$} \\
\hline $\begin{array}{l}\text { Mental Health } \\
\text { Treatment } \\
\text { Model }\end{array}$ & & & & \\
\hline $\begin{array}{l}\text { Any Mental } \\
\text { Health } \\
\text { Treatment }\end{array}$ & $.452 *$ & .169 & 1.571 & {$[1.129,2.186]$} \\
\hline $\begin{array}{l}\text { Psych. } \\
\text { Evaluations }\end{array}$ & -.073 & .039 & .930 & {$[.862,1.003]$} \\
\hline $\begin{array}{l}\text { Total } \\
\text { Number of } \\
\text { Illicit Drugs } \\
\text { Used in } \\
\text { Past Year }\end{array}$ & $.181 *$ & .078 & 1.198 & {$[1.028,1.397]$} \\
\hline $\begin{array}{l}\text { Average } \\
\text { Monthly } \\
\text { Income }\end{array}$ & $-.445 *$ & .223 & .641 & {$[.414, .992]$} \\
\hline $\begin{array}{l}\text { Financial } \\
\text { Assistance } \\
\text { Model }\end{array}$ & & & & \\
\hline $\begin{array}{l}\text { Social } \\
\text { Security or } \\
\text { Disability }\end{array}$ & $-.421 *$ & .154 & .656 & {$[.485, .887]$} \\
\hline $\begin{array}{l}\text { Total } \\
\text { Number of } \\
\text { Illicit Drugs } \\
\text { Used in } \\
\text { Past Year }\end{array}$ & .145 & .075 & 1.156 & {$[.999,1.337]$} \\
\hline
\end{tabular}




\section{Post-Hoc Analyses}

After examining the results of the individual models, it was decided that two posthoc analyses would be performed. First, the decision was made to conduct a final posthoc regression analysis to further access how the retained variables from each of the three models predicted recidivism, which therefore provided data on what independent variables most affected the criminal justice outcomes of the women in the study. Second, a descriptive analysis was conducted to determine the specific types of charges that resulted in incarcerations for the participants who identified recidivating at the T2 and T3 interviews. This analysis was performed in order to obtain a better understanding of the specific offenses that resulted in incarcerations among the participants and to provide additional descriptive context for interpreting the results from the recidivism analyses. The descriptive analysis was conducted through determining the percentage that each charge that ended up resulting in incarcerations represented within the total number of times participants recidivated over the course of the study.

\section{Post-Hoc Regression Analysis}

A final post-hoc model utilizing the variables retained in the three regression analyses was conducted. The following independent variables were entered into the posthoc regression model: (1) the total number of times the participant identified receiving any drug or alcohol treatment in the previous 12 months at the baseline, T2, and T3 interviews; (2) the total number of times the women reported receiving any mental health treatment in the previous 12 months at the baseline, T2, and T3 interviews; (3) the cumulative number of times the participants identified receiving a psychological evaluation in the past 12 months at the baseline, T2, and T3 interviews; (5) the total 
number of times the participants reported receiving social security or disability in the last 30 days during the baseline, $\mathrm{T} 2$, and $\mathrm{T} 3$ interviews; and (6) the average monthly incomes of the women over the past 12 months as reported at the baseline interview. In addition, the control variable that measured the total number of illicit drugs the participants identified using in the previous 12 months at the baseline interview were also entered into the model.

The results of the final model from the post-hoc analysis are listed in Table 6. The post-hoc model accounted for $19 \%$ of the variance in recidivism (Nagelkerke $R^{2}=.19$ ). Four variable were retained in the final model, including the total number of times the participants reporting receiving any drug or alcohol treatment in the past 12 months throughout the study, the total number of times in which the participants identified receiving any mental health treatment in the past 12 months during the study, the total number of times the participants reported receiving social security or disability in the previous 30 days throughout the study, and the total number of times the participant identified having a psychological evaluation in the previous 12 months during the study. Three of the variables in the final model reach the conventional level of significance. Specifically, each point during the study in which the participants identified receiving social security or disability during the previous 12 months was associated with a $40 \%$ decrease in the likelihood of recidivating., $B=-.510$, Wald $\chi^{2}=9.464, p=.002, \exp (B)=$ .601. In addition, each point of the study in which the participants identified receiving any drug or alcohol treatment in the previous 12 months was associated with a $47 \%$ increase in the odds of recidivating, $B=.382$, Wald $\chi^{2}=9.464, p=.003, \exp (B)=$ .1.47. Also, each time throughout the study in which participants reported receiving 
mental health treatment was associated with a $43 \%$ increase in the odds of recidivating, $B$ $=.363$, Wald $\chi^{2}=6.549, p=.010, \exp (B)=.1 .43$. 
Table 10.

Final Logistic Regression Post-Hoc Model Predicting Recidivism

\begin{tabular}{|c|c|c|c|c|}
\hline Variables & Beta & Standard Error & Odds Ratio & $95 \% \mathrm{CI}$ \\
\hline $\begin{array}{l}\text { Any Drug or } \\
\text { Alcohol } \\
\text { Treatment }\end{array}$ & $.401 *$ & .132 & 1.493 & {$[1.153,1.933]$} \\
\hline $\begin{array}{l}\text { Any Mental } \\
\text { Health } \\
\text { Treatment }\end{array}$ & $.568 *$ & .183 & 1.764 & {$[1.232,2.525]$} \\
\hline $\begin{array}{l}\text { Psychological } \\
\text { Evaluation }\end{array}$ & -.076 & .042 & .927 & {$[.853,1.007]$} \\
\hline $\begin{array}{l}\text { Social Security } \\
\text { of Disability }\end{array}$ & $-.510 *$ & .166 & .601 & {$[.434, .831]$} \\
\hline
\end{tabular}




\section{Post-Hoc Descriptive Statistics of the Charges that Led to Incarcerations}

The analysis of the descriptive statistics pertaining to the charges that led to incarcerations for the participants who recidivated are listed in Table 7 . The results from this analysis indicated the participants were incarcerated a total of 127 times over the course of the study, 64 of which occurred between the T1 and T2 interviews and 63 between the $\mathrm{T} 2$ and $\mathrm{T} 3$ interviews. The charges that led to the most incarcerations among the participants at the T2 and T3 interviews were probation violations (34.7\%), while the next highest number included shoplifting/vandalism (13.4\%), drug offenses (10.2\%), assault (5.5\%), contempt of court (4.7\%), and burglary/larceny (3.9\%). A fewer number of the participants were incarcerated as a result of forgery $(2.4 \%)$, weapons offenses $(1.6 \%)$, robbery $(0.8 \%)$, and prostitution $(0.8 \%)$. Additionally, a significant number of the participants became incarcerated from charges that were not included in the WHRS survey $(22.0 \%)$. 
Table 11.

Charges Leading to Recidivism Among the Participants $(n=127)$

\begin{tabular}{lccc}
\hline Type of Charge & $\begin{array}{c}\% \text { of } \\
\text { Incarcerations } \\
\text { at T2 } \\
(n=64)\end{array}$ & $\begin{array}{c}\text { \% of } \\
\text { Incarcerations } \\
\text { at T3 } \\
(n=63)\end{array}$ & $\begin{array}{c}\text { \% of Total } \\
\text { Incarcerations } \\
\text { at T2 and T3 } \\
(n=127)\end{array}$ \\
\hline Shoplifting/Vandalism & 14.1 & 12.7 & 13.4 \\
Probation Violation & 34.4 & 35.0 & 34.7 \\
Drug Charge & 6.3 & 14.3 & 10.2 \\
Forgery & 3.1 & 1.6 & 2.4 \\
Weapons Offense & 1.6 & 1.6 & 1.6 \\
Burglary/Larceny & 6.3 & 1.6 & 3.9 \\
Robbery & 0 & 1.6 & 0.8 \\
Assault & 4.7 & 6.3 & 5.5 \\
Prostitution & 1.6 & 0.3 & 0.8 \\
Contempt of Court & 3.1 & 19.0 & 4.7 \\
Other & 25.0 & & 5.0 \\
\hline
\end{tabular}




\section{CHAPTER V}

\section{DISCUSSION}

The objectives of this study were to examine the affect of substance use treatment, mental health treatment, employment services, government financial assistance, race/ethnicity, and income on the recidivism outcomes of women on probation. Several interesting findings are presented in this study pertaining to the affect of substance use treatment, mental health treatment, and government financial assistance on the criminal justice outcomes of female probationers. The results identify that participants who received social security or disability at more points during the study were less likely to recidivate, while the utilization of substance use and mental health treatment increased the occurrence of recidivism. The findings also demonstrate that several of the disadvantages common among female probationers, including substance use, mental health issues, and income, resulted in a greater likelihood of the participants recidivating. This section reviews the relevant findings of the study while also discussing its implication for future policy and research as well as information on its limitations.

\section{Financial Assistance and Reductions in Recidivism}

The participants who received social security or disability at more points during the study were less likely to recidivate according to the results from the bivariate and regression analyses. This finding strongly suggests particular services improve the criminal justice outcomes of female probationers. Specifically, forms of financial assistance such as social security or disability could provide needed monetary support to 
women on probation given that the population frequently experiences poverty (ChesneyLind \& Pasko, 2013; Vera Institute of Justice, 2016). This assertion is consistent with another finding that indicated that living in poverty significantly increased the likelihood of recidivism among a sample of female probationers (Holtfreter, Reisig, \& Morash, 2004).

Among the overall sample for this study, nearly $90 \%$ of the participants identified their average monthly income was less than $\$ 1,000$ dollars $^{11}$, while $70 \%$ indicated their work status was either unemployed or disabled. Therefore, it is possible that receiving social security or disability during the study helped to offset the financial challenges confronting the participants (Chesney-Lind \& Pasko, 2013; Vera Institute of Justice, 2016). For instance, a report by the ACLU (2016) identified that probation sentences present considerable financial obstacles for offenders, including fees associated with supervision, drug testing, substance use treatment, mental health treatment, legal fines, and/or transportation to and from meetings. Furthermore, female offenders often have limited access to SNAP, TANF, and public housing from felony-level drug convictions and encounter difficulties finding well-paying jobs due to limited marketable job skills, criminal records, and bans from obtaining professional licenses (Chesney-Lind \& Pasko, 2013; Opsal, 2012, 2015).

As such, financial assistance (social security, disability or otherwise) represents a more rehabilitative and supportive approach to helping female offenders during sentences. For instance, monetary assistance may help female probationers afford the costs of probation and lessen the economic struggles associated with living in poverty.

${ }^{11}$ According to the U.S. Census Bureau, the federal poverty line in the U.S. is $\$ 1,011$ per month for one person. 
Also, given the affect of poverty on criminal justice outcomes as identified in previous research (Holtfreter et al., 2004), expanding financial assistance to more female probationers should be considered in the greater context of developing policies that assist with successfully completing their sentences.

\section{Substance Use Treatment and Recidivism Outcomes}

The results from the bivariate and regression analyses identified a relationship between the reception of more drug or alcohol treatment and recidivism. In particular, the participants who received drug or alcohol treatment at more points during the study had a greater likelihood of recidivating. This finding is in contrast to the existing research indicating that substance use treatment reduces recidivism for women offenders following their release from prison (Covington, 2008; Messina, Grella, Cartier, \& Torres, 2010; Swopes, Davis, \& Scholl, 2015; Wolff, Frueh, Shi, \& Schumann, 2012; Zlotnick, Johnson, \& Najavitis, 2009). The present research therefore raises several questions about other factors that contributed to recidivism among the participants, such as the level of monitoring they received and the influence of drug use on the requirements for completing their sentences.

Probationers take a risk/needs assessment at the beginning of their sentences in which the conditions of their supervision are decided (Chesney-Lind \& Pasko, 2013; Phelps, 2013). During this assessment, the level of supervision probationers are placed under is significantly affected by prior/current drug and alcohol use (Chesney-Lind \& Pasko, 2013). Specifically, probationers with past and/or current substance use histories are often ordered to participate in drug and alcohol treatment services and issued stricter supervision requirements, such as frequent drug screenings (ACLU, 2016; Chesney-Lind 
\& Pasko, 2013; Phelps, 2013; Vera Institute of Justice, 2013). As a result, receiving technical violations from drug screenings are more likely to occur for those who are in treatment and under stricter forms of supervision. The findings from this study may reflect a similar phenomenon; women in substance use treatment may have received higher levels of supervision and been mandated to meet additional requirements, thus resulting in higher incidences of recidivating than women not participating in these sanctions. In fact, results from a post-hoc analysis indicate that probation violations represented the greatest percentage of charges leading to incarcerations among the participants in this study (34.7\%), therefore suggesting that those who recidivated may have done so through violating the conditions of their supervision from positive drug screenings.

\section{Mental Health Treatment and Recidivism Outcomes}

The findings from the bivariate and regression analyses on the affect of mental health treatment on recidivism identified that participants who received mental health treatment at more points during the study had a greater likelihood of recidivating. Similar to substance use treatment utilization, this finding conflicts with the existing research on the affects of mental health services on recidivism among female prisoners. Specifically, previous studies indicated that services to address mental health issues improve the postincarceration criminal justice outcomes of female prisoners (Covington, 2008; Messina, Grella, Cartier, \& Torres, 2010; Swopes, Davis, \& Scholl, 2015; Wolff, Frueh, Shi, \& Schumann, 2012; Zlotnick, Johnson, \& Najavitis, 2009). This begs the question of what specific factors the participants in mental health treatment could have had to increase the likelihood of recidivism. 
The relationship between more mental health treatment utilization and recidivism could be associated with mental health issues increasing negative criminal justice outcomes as well as the affects of the co-occurrence of substance use disorders and mental illness for which is frequent among women offenders. Probationers who partake in mental health treatment during their sentences are usually mandated to do so as a condition of their supervision since they are considered by the criminal justice system to have mental health issues (Phelps, 2013; Vera Institute of Justice, 2016). Also, prior research indicates that female probationers with mental health issues (specifically depression and anxiety) are more likely to recidivate than those without these conditions (Salisbury \& Van Voorhis, 2009). Therefore, the women in the study who partook in more mental health treatment may have been experiencing mental health issues that increased their likelihood of recidivating.

Furthermore, previous research has indicated that female offenders often experience co-occurrences of mental illness and substance use disorders (Chesney-Lind \& Pasko, 2013; Covington, 2008). Relatedly, each of the participants in the present research experienced at least one instance of physical or sexual victimization, which suggests they were even more likely to develop co-occurring mental illnesses and substance use disorders (Chesney-Lind \& Pasko, 2008; Covington, 2008). As such, the participants with mental health issues may have been more likely to experience recidivism from having a positive drug screening given the high rate of women in this study who recidivated from violating the conditions of their supervision (34.7\%) (Chesney-Lind \& Pasko, 2013; Covington, 2008). 


\section{Treating Substance Use and Mental Health Issues}

Several of the findings from this study raised questions about the procedures probation departments are using to supervise offenders with substance use and/or mental health issues. The fact that participants with substance use and/or mental health issues were incarcerated at higher rates suggests the U.S. criminal justice system may be providing inadequate treatment services to probationers. This casts doubt on whether U.S. probation departments are functioning as effective diversions for incarceration or rather operating to imprison female offenders who have substance use and/or mental health issues.

While the WHRS did not collect data on the types of interventions received by the participants who accessed substance use and/or mental health treatment, since recidivism was more common among the women who accessed treatment, the services received by the participants in this study may have lacked a proven evidence-base for effectiveness. Therefore, providing evidence-based treatment to female probationers could ensure the most effective interventions are provided during sentences. For instance, Helping Women Recover/Beyond Trauma is an intervention that combines cognitive-behavioral group therapy, psycho-education, art therapy, and meditation to address issues common to female offenders, such as substance use, mental illness, and victimization (Covington, 2008). Multiple studies of Helping Women Recover/Beyond Trauma have identified its effectiveness at addressing issues identified in the pathways perspective as common to women offenders, such as substance use, victimization, and mental health issues (Covington, 2008; Messina, Grella, Cartier, \& Torres, 2010; Swopes, Davis, \& Scholl, 2015; Wolff, Frueh, Shi, \& Schumann, 2012; Zlotnick, Johnson, \& Najavitis, 2009). 
Furthermore, Helping Women Recover/Beyond Trauma includes a group therapy component in which the participants are encouraged to develop relationships with one another based on their shared experiences with victimization and addiction (Covington, 2008). These relationships are intended to address the long-standing abuse histories frequent among women offenders by creating a support system, and could therefore help develop a form of social capital among the participants. The focus of Helping Women Recover/Beyond Trauma on empowering female offenders and building relationship could function as an effective intervention for increasing social capital while also reducing the likelihood of recidivism.

\section{Race/Ethnicity and Probation}

The racial/ethnic proportionality in the sample for the present research was similar to regional and national data as African Americans represented $48.2 \%$ of the women in this study, which is more than both White participants (44.1\%) and a third category of all other racial/ethnic groups (7.7\%). In order to determine the affects of race/ethnicity on recidivism among the participants, race/ethnicity was examined in the substance use treatment, mental health treatment, and financial assistance regression analyses and the bivariate analysis. These analyses found that race/ethnicity had no significant affect on recidivism in any of the analyses, which was unexpected given the prior research indicating that African Americans are more likely to experience probation recidivism and therefore warranted further exploration (Alexander, 2010; Zinn, 1980).

Race/ethnicity (particularly when operationalized as a categorical construct) often acts as a 'proxy variable' for other phenomena and processes. Most relevant to the current research, systemic discrimination based on race/ethnicity in the U.S., often leads 
to fewer economic and educational opportunities for African Americans (Chang, 2010; Collins \& Bilge, 2016; Zinn, 1980), factors that individually and in combination with one another contribute to recidivism among female probationers generally and African American female probationers specifically (Alexander, 2010; Steinmetz \& Henderson, 2016). Therefore, an analysis was performed to examine whether underlying racial differences existed between the participants in terms of their income and education ${ }^{12}$. However, the results of these analyses found no significant racial differences among the participants in regard to income and education level. Thus, while race/ethnicity clearly affects the overrepresentation of African American females in the criminal justice system, the affects of race/ethnicity on recidivism is less obvious, and perhaps more nuanced among women on probation.

The null findings in regard to race/ethnicity suggest, in part, that the cumulative disadvantages among the participants (i.e., substance use, mental health issues, and income) may trump the affects of race/ethnicity alone among this population. Specifically, considering the frequency of recent illicit drug use $(66.1 \%$ of the participants report illicit drug use within the past two years at baseline) and the probation requirement to abstain from drug use, technical violations from positive drug screenings and additional drug charges may be a frequent occurrence among the women. As evidence, violation of the conditions of probation was the most common reason women reported recidivating during this study $(34.7 \%)$ while drug-related charges also resulted in recidivism for a portion of the sample (10.2\%). Furthermore, the bivariate analysis

${ }^{12}$ The results from the post-hoc analysis are listed in Table A1 of the appendix. 
demonstrated that participants who utilized more illicit drugs in the past year at baseline were more likely to recidivate.

Despite the findings from the present study, the affects of racial bias in the criminal justice system are well documented (Alexander, 2010; Mauer \& King, 2007; Steinmetz \& Henderson, 2016). It is possible that a more nuanced approach, that more specifically examines the context of probation for women, is necessary to fully understand the affects of race/ethnicity among this population. For example, currently missing from the probation literature is self-reported data by African Americans regarding possible experiences with discrimination and bias; data which could provide important information on the factors influencing criminal justice outcomes. Furthermore, a multivariate examination of possible within group differences between African Americans women could provide more comprehensive data on the varying levels of discrimination experienced among the population.

\section{Practice and Policy Implications}

\section{Expanding Affordable Evidence Based Treatment}

The current study found that the treatment services provided to female probationers were ineffective at reducing occurrences of recidivism. This finding has important implications for expanding access to treatment services to improve criminal

justice outcomes. The reception of treatment services with a proven evidence-based could decrease recidivism among female probationers by ensuring the best interventions are available to the offenders in need of treatment, such as the aforementioned Helping Women Recover/Beyond Trauma. 
Recent expansions in the availability of substance use treatment through the Patient Protection and Affordable Care Act (ACA) increases the availability of treatment services for the criminal justice population (Watkins, Farmer, De Vries, \& Hepner, 2015). Several states have already implemented procedures to expand access to treatment for probationers through placing a deliberate emphasis on arranging services. For example, the probation departments in Hawaii, Arizona, and Oregon expanded treatment services and this resulted in greater service utilization in addition to reductions in the number of technical violations and revocations received by offenders (The Pew Center on the States, 2011). Broadly, these changes involved providing access to substance use or mental health treatment for individuals considered at higher risk of committing technical violations, implementing more evidence-based interventions, and increasing collaboration between probation officers, courts, and treatment providers to ensure treatments were provided (The Pew Center on the States, 2011).

For example, a statewide program in Hawaii called Hawaii's Opportunity Probation with Enforcement (HOPE) program includes collaboration between police, prosecutors, and treatment providers to ensure that individuals considered at greater risk of committing probation violations have access to substance use or mental health treatment (PEW Center on the States, 2011). A randomized controlled trial of HOPE, which included 504 probationers, $25 \%$ of whom were women, found significant reductions in revocations and rearrests for the participants who received the services in comparison to a control group (PEW Center on the States, 2011). Furthermore, the probation departments in Arizona and Oregon have also emphasized evidence-based practices in the treatment of offenders, which has led to reductions in the number of 
technical violations and revocations received by the probationers (PEW Center on the States, 2011).

Despite these positive signs in terms of expanding treatment access and subsequent reductions in recidivism, Chesney-Lind \& Pasko (2013) did an evaluation of the probation departments in all 50 U.S. states and found that most do not offer interventions that specifically address the issues common to female offenders, such as the relationship between substance use disorders, mental health issues, and victimization. As such, the organizational structures that have been employed at the probation departments in Hawaii, Oregon, and Arizona, in which key players such as prosecutors, judges, probation officers, and treatment providers collaborate with one another to expand treatment options, could also include interventions specifically designed for female probationers.

\section{Altering Supervision Procedures}

One of the issues that emerged from this study was how probation violations and drug-related crimes were the main charges that resulted in recidivism among the participants. Specifically, probation violations accounted for the most charges that led to recidivism (34.7\%), while drug-related offenses represented the third largest $(10.2 \%)$. Based on this information, it is possible to hypothesize that the challenges of meeting probation conditions would be less severe if more focus were placed on rehabilitation instead of punishment. Previous research has noted that the pressures to meet probation requirements create unreasonable expectations and additional stress for offenders (ACLU, 2016; Opsal, 2009). For example, Opsal (2009) conducted a qualitative study of 43 women on parole and found that most of the participants viewed community 
supervision as a means by which to reincarcerate them through the frequent drug testing

and constant monitoring. Furthermore, a report by the ACLU (2016) indicated that some defense attorneys advise their clients to take jail sentences since the expectations for meeting the requirements of community supervision are extremely difficult to meet.

Another aspect of probation supervision that could be altered pertains to the consequences for positive drug screenings. Specifically, testing positive for illicit drug use represents one of the main contributing factors to revocations among female probationers (ACLU, 2016; Olson, Lurigio, \& Alderden, 2003; Salisbury \& Van Voorhis, 2009). As such, changing the requirements of probation sentences to focus more on treatment for drug-related issues could have a positive affect on criminal justice outcomes.

\section{Expanding Access to Financial Assistance and Employment Opportunities}

The findings of this study provide evidence to suggest that the reception of financial support could have a positive affect on criminal justice outcomes. Some of the issues emerging from this finding relate to the need to address the financial challenges of completing probation sentences, especially given the relationship between poverty and recidivism (Olson, Lurigio, \& Alderden, 2003). As such, it could be helpful to develop targeted interventions aimed at providing monetary assistance to female probationers who are experiencing financial difficulties during their sentences. This could subsequently assist women probationers with affording needed treatment and supervision/court fines.

Another policy that could reduce the financial strain offenders often encounter includes removing bans on SNAP, TANF, subsidized housing, and employment options for offenders who have criminal convictions (ACLU, 2016; Alexander, 2010; Vera 
Institute of Justice, 2016). Also, the eradication of policies that limit individuals with criminal records from accessing many professional licenses, ranging from taxi driver to massage therapist, could improve the financial circumstances of female probationers (ACLU, 2016). Taken together, these suggestions could have a significant impact on both improving the criminal justice outcomes and limiting the financial strains placed on female probationers.

\section{Eliminating Racially Discriminatory Policing}

Several changes could address the racially discriminatory policing policies often directed toward African Americans by the criminal justice system. These policy changes include abolishing the discriminatory policing practices that increase the number of African Americans in the probation population. More specifically, eliminating the overpolicing of predominantly African American communities and discontinuing the quotas that require officers to make a minimum number of arrests each month could reduce the racial disproportionality within the criminal justice population (ACLU, 2016; Sentencing Project, 2017). Possible methods for facilitating these changes include requiring law enforcement to ban racial profiling and also collecting data on the race/ethnicity of each person who receives a pedestrian or traffic stop, both of which could reduce instances of racial inequality in policing (ACLU, 2016).

\section{Implications for Social Work Practice in the Criminal Justice System}

Social workers represent the largest number of mental health and substance use clinicians in the U.S. and historically have taken on important roles in treating both of those issues (CSWE, 2014). Therefore, expanding social work practice to have a more specific focus on working with the female criminal justice population could improve 
recidivism outcomes. In particular, employing the strengths perspective as a guiding principle for engaging with justice-involved individuals could generate a more rehabilitative alternative to the punitive supervision frequently placed on offenders, while the person-in-environment perspective could help to address the multidimensional issues often affecting female probationers in a more comprehensive manner (CSWE, 2014). Furthermore, the social work value associated with respecting the dignity and worth of all people could be an important aspect of practice with justice-involved individuals given the history of stigma directed toward the U.S. criminal justice population (Mauer \& King, 2007).

\section{Limitations}

As a secondary data analysis, the current study was limited to data that did not specifically focus on the affect of treatment services on recidivism. As such, there were several limitations to this study that should be acknowledged. A discussion of these limitations is included in the following section.

\section{Lacking Information on the Types of Interventions}

The current research was unable to analyze the specific types of substance use or mental health interventions received by the participants. Aside from one variable regarding 12-step participation, the WHRS did not include any data on the interventions

provided to the participants. This presents a limitation in terms of analyzing the affect of the services on probation recidivism since no information was available on whether the interventions received by the participants had an evidence-base. Certain interventions have been proven to be effective at reducing recidivism outcomes among female offenders, such as the aforementioned Helping Women Recover/Beyond Trauma 
(Covington, 2008). As such, data on the types of treatment provided to the participants would have assisted in evaluating the affect of the treatment services on the criminal justice outcomes among the participants.

\section{Affect of Probation Officers on Recidivism Outcomes}

The current research was not designed to evaluate the techniques probation officers utilized to supervise the participants. Most specifically, the WHRS did not include data on how probation officers interacted with the participants or their decisionmaking process for giving them technical violations or revocations. Previous research indicates the existence of differences among probation officers in regard to their supervision of offenders, as some threaten incarcerations while others focus on encouragement and service coordination (ACLU, 2016; Draine \& Solomon, 2001; Skeem, Louden, \& Polaschek, 2007). The available evidence suggests the manner in which probation officers supervise offenders can impact recidivism outcomes. In particular, one study found that offenders who identified higher levels of fairness and trust in their relationships with probation officers were less likely to receive technical violations and revocations, while those who rated the probation officers highest on levels of toughness were more likely to recidivate (Skeem, Louden, \& Polaschek, 2007).

The current investigation was therefore limited by the absence of data on the supervision techniques of the probation officers. Given that probation officers have the power to determine the criminal justice outcomes of the participants, their supervision techniques could have affect the criminal justice outcomes of the participants in this study. Depending on whether of not individual probation officers took a more supportive 
approach to supervising the participants in this study could have made a difference in terms of criminal justice outcomes.

\section{Directions for Future Research}

The present research generated several questions that are in need of further investigation. Additional research could help to establish a greater understanding of services that could improve the criminal justice outcomes of the women on probation. In particular, it is suggested that future studies investigate the treatment infrastructure available to female probationers in order to determine the types of substance use and mental health interventions available to the population. More research of the specific treatment services would provide information on the treatments that could help improve criminal justice outcomes for the population, which is currently lacking in the literature.

It is also recommended that research be undertaken to more thoroughly evaluate the impact that race/ethnicity has on the probation outcomes of female offenders. For instance, future research could explore the topic of race/ethnicity and racial discrimination by studying the ways in which probation departments supervise offenders. Additionally, the recommendations for future research also include examination of between-group differences among African American women regarding experiences with discrimination.

It is also recommended for further research to be conducted on the potential affect of financial support on reducing the occurrences of recidivism for female probationers. The finding from this study related to reductions in recidivism among the participants who received more social security or disability provides evidence that financial support could have a positive impact on the criminal justice outcomes of female probationers. 
Additional research should therefore evaluate whether this finding could be replicated in future studies.

\section{Study Conclusions}

The findings from this study add to our understanding of services for which could improve the criminal justice outcomes of women on probation. One of the more significant findings to emerge was that the participants who received more social security or disability during the study recidivated less often. The second major finding was that incarcerations were more common for the women who had greater instances of receiving any substance use or mental health treatment. Several findings from this study were less surprising, such as drug use and poverty increasing recidivism, and therefore confirm previous research pertaining to the factors that increase recidivism among female probationers. Taken together, the results from the present research shine a light on the possibility that financial assistance could improve the criminal justice outcomes of female probationers and also provides an indication of the current limitations in regard to the services that address issues common among women offenders, such as substance use and mental health treatment. 


\section{REFERENCES}

Alexander, M. (2010). The new Jim Crow: Mass incarceration in the age of colorblindedness. New York, NY: New Press

Allard, P. (2002). Life sentences: Denying welfare benefits to women convicted of drug offenses. The Sentencing Project. Washington, DC.

American Civil Liberties Union. (2016). Every 25 seconds: The human toll of criminalizing drug use in the United States. Washington, DC.

Beckett, K., Nyrop, K. Pfingst, L. (2006). Race, drugs, and policing: Understanding disparities in drug delivery arrests. Criminology, 44(1), 105-137.

Berkwits, M., \& Inui, T.S. (1998). Making use of qualitative research techniques. Journal of General Internal Medicine, 13, 195-199.

Bloom, B., Owen, B., \& Covington S. (2003) Gender-responsive strategies:

Research, practice, and guiding principles for women offenders. Washington, D.C.: National Institute of Corrections.

Bonczar, T. (2003). Prevalence of imprisonment in the U.S. population, 1974-2001. Washington, DC: Bureau of Justice Statistics.

Bourdieu, P. (1986). The forms of capital. In J.G. Richardson (Ed.)., Handbook of theory and research for the sociology of education pp. 241-258). New York: Greenwood.

Bronson, J., \& Berzofsky, M. (2017). Indicators of mental health problems reported by 
prisoners and jail inmates, 2011-12. Washington, D.C.: U.S. Department of Justice.

Carson, E.A., \& Anderson, E. (2016). Prisoners in 2015. Washington, DC: Bureau of Justice Statistics.

Center for Behavioral Health Statistics and Quality. (2015). Behavioral health trends in the United States: Results from the 2014 National Survey on Drug Use and Health. Retrieved from http://www.samhsa.gov/data/

Chang, M. (2010). Lifting as we climb: Women of color, wealth, and American's future. Insight Center for Community Economic Development.

Chesney-Lind, M. (2000). What to do about girls? Thinking about programs for young women. In M. McMahon (Ed.)., Assessment to assistance. Programs for women in community corrections (pp. 139-170. Lanham, MD: American Correctional Association.

Chesney-Lind, M., \& Pasko, L. (2013). The female offender: Girls, women and crime ( $2^{\text {nd }}$ ed.). Thousand Oaks, CA: Sage.

Christy, A., Polythress, N.G., Boothroyd, R.A., Petrila, J., \& Mehra, S. (2005). Evaluating the efficiency and community safety goals of the Broward County mental health court. Behavioral Science Law, 23(2), 227-243.

Coleman, J. (1988). Social capital in the creation of human capital. American Journal of Sociology, 94(Supplement), S95-S-120.

Collins, P.H., \& Bilge, S. (2016). Intersectionality. Malden, MA: Polity.

Comack, E., Chopyk, V., \& Wood, L. (2000). Mean streets? The social locations, 
gender, dynamics and patterns of violent crime in Winnipeg: Canadian Centre for Policy Alternatives.

Cosden, M., Ellens, J.K. Schnell, J.L., Yamini-Diouf, Y., \& Wolfe, M.M. (2003).

Evaluation of a mental health treatment court with assertive community treatment. Behavioral Science Law, 21(4), 415-427.

Covington, S.S. (2008). Women and addiction: A trauma-informed approach. Journal of Psychoactive Drugs, 40(S5), 377-385.

Cummings, J.R., Wen, H., Ko, M., \& Druss, M.D. (2014). Race/ethnicity and geographic access to medicaid substance use disorder treatment facilities in the United States. JAMA Psychiatry, 71(2), 190-196.

Daly, K. (1992). Women's pathways to felony court: Feminist theories of lawbreaking and problems of representations. S.Cal. Rev. L. \& Women's Stud. 2, 11-52.

Daly, K. (1994). Gender, crime, and punishment: Yale University Press.

De Li, S., \& MacKenzie, D.L. (2003). The gendered effects of adult social bonds on the criminal activities of probationers. Criminal Justice Review, 28(2), 278298.

Derogatis, L.R., \& Melisaratos, N. The Brief Symptom Inventory: An introductory report. Psychological Medicine, 13(3), 595-605.

Dodge, M., \& Pogrebin, M,R. (2001). Collateral costs of imprisonment for women: Complications of reintegration. The Prison Journal, 81(1), 42-54.

Draine, J., Solomon, P. (2001). Threats of incarceration in a psychiatric probation and parole service. American Journal of Orthopsychiatry, 71(2), 262-267. 
Durose, M., Smith, E.L., Langan, P.A. (2007). Contacts between police and the public. Washington, D.C.: Bureau of Justice Statistics.

Eisenburg, M., Bryl, J., Fabelo, T. (2009). Validation of the Wisconsin department of correction risk assessment instrument. New York, NY: Council of State Governments Justice Center.

Epp, C.R., Maynard-Moody, S., \& Haider-Markel, D.P. (2014). Pulled over: How police stops define race and citizenship. Chicago, IL: The University of Chicago Press.

Glaze, L.E., \& Maruschak, L.M. (2010). Parents in prison and their minor children. Washington, D.C.: Bureau of Justice Statistics.

Golder, S., Hall, M.T., Logan, T.K., Higgins, G.E., Dishon, A., Renn, Y., \& Winham, K.M. (2014). Substance use among victimized women on probation and parole. Substance Use \& Misuse, 49, 435-447.

Goodale, G., Callahan, L., \& Steadman, H.J. (2013). Law \& psychiatry: What we can say about mental health courts today? Psychiatric Services, 64(4), 298-300.

Gray, M.K., Fields, M. (2001). Examining probation violations: Who, what, and when. Crime \& Delinquency, 47(4), 537-557.

Greenfeld L.A., \& Snell T.L. (1999). Women Offenders. Washington, D.C.: Bureau of Justice Statistics.

Harlow, C.W. (2003). Education and correctional populations. Retrieved from Washington, D.C.

Heath, B. (2014). Racial gap in U.S. arrest rates: 'Staggering Disparity.' USA Today. Henderson, H. (2006). The predictive utility of the Wisconsin Risks Needs 
Assessment Instrument in a sample of Texas probationers. Dissertation Abstracts International, 68(02), 1-86.

Henderson, H., Adams, D.A., Rembert, D. (2007). The predictive utility of the Wisconsin Risk Needs Assessment Instrument in post-probation success. International Journal of Crime, Criminal Justice, and Law, 2, 95-103.

Holtfreter, K., Reisig, M.D., \& Morash, M. (2004). Poverty, state capital, and recidivism among women offenders. Criminology and Public Policy, 3(2), 185208.

Huddleston, W., \& Marlow, D. (2011). Painting the current picture: A national report on drug courts and other problem-solving courts. National Drug Court Institute.

Huebner, B.M., \& Cobbina, J. (2007). The effect of drug use, drug treatment participation, and treatment completion on probation recidivism. Journal of Drug Issues, 37(3), 619-641.

Huey, M.P., \& McNulty, T.L. (2005). Institutionnel conditions and prison suicide: Conditional effects of deprivation and overcrowding. The Prison Journal, 85(4), 490-514.

Jamieson, J., McIvor, G., \& Murray, C. (1999). Understanding offending among young people. Edinburgh : The Stationery Office.

Jannetta, J., Breaux, J., \& Ho, H. (2014). Examining racial and ethnic disparities in probation revocation. The Urban Institute.

Johnson, I.M. (2014). Economic impediments to women's success on Parole: "We need someone on our side." The Prison Journal. 94(3), 365-387.

Justice Center: The counsel on state governments (2013). Justice reinvestment in 
Kansas: Analysis \& policy options to reduce spending on corrections and reinvest in strategies to increase public safety. Retrieved from https://csgjusticecenter.org/wp-content/uploads/2013/08/Kansas-JR-FinalReport.pdf

Kaeble, D., Bonczar, T.P., \& BJS Statistics (2016). Probation and parole in the United States, 2015. Washington, DC: Bureau of Justice Statistics.

Kentucky Division of Probation and Parole (2014). Offender handbook.

Kupers, T. (1999). Prison madness: The mental health crisis behind bars and what we must do about it. San Francisco: Jossey-Bass

Langan, P.A., \& Cunniff, M.A. (1992). Recidivism of felons on probation. Washington, DC: Bureau of Justice Statistics.

Langton, L., \& Durose, M. (2013). Police behavior during traffic and street stops, 2011. Washington, DC: Bureau of Justice Statistics.

Leverentz, A. (2011). Being a good daughter and sister: Families of origin in the reentry of African American female ex-prisoners. Feminist Criminology, 6(4), 239267.

Lin, N. (1999). Building a network theory of social capital. Connections, 22(1), 28-51. Mallicoat, S. (2011). Women and crime: A text/reader. Thousand Oaks, CA: Sage. Marlowe, D.B. (2003). Integrating substance abuse treatment and criminal justice supervision. Science \& Practice Perspectives, 4-14.

Mauer, M., \& King, R.S. (2007). A 25-year quagmire: The war on drugs and its impact on American society. Retrieved from 
http://www.sentencingproject.org/publications/a-25-year-quagmire-the-waron-drugs-and-its-impact-on-american-society/

Merton, R. (1988). The Matthew effect in science II: Cumulative disadvantage and the symbolism of intellectual property. ISIS, 79, 606-623.

Messina, N., Grella, C.E., Cartier, J., \& Torres, S. (2010). A randomized experimental study of gender-responsive substance abuse treatment for women in prison. Journal of Substance Abuse Treatment, 38(2), 97-107.

Meyers, L.S., Gamst, G., Guarino, A.J. (2013) Applied multivariate research. Thousand Oaks, CA: Sage.

Moore, M.E., \& Hiday, V.A. (2006). Mental health court outcomes: A comparison of rearrest and re-arrest severity between mental health court and traditional court participants. Law and Human Behavior, 30(6), 659-674.

Mumola, C.J., \& Karberg, J.C. (2007). Drug use and dependence, state and federal prisoners, 2004. Washington, D.C.: U.S. Department of Justice.

National Women's Law Center. (2017). The wage gap: The who, how, why, and what to do. Washington D.C.

Newman, J.C., Jarlais, D.C.D., Turner, C.F., Gribble, J., Cooley, M.S., \& Paone, D. (2002). The differential effects of face-to-face and computer interview models. American Journal of Public Health, 92(2), 294-297.

Nova Research Company (2003). QDS Questionnaire Development System. Retrieved from http://novaresearch.com

Olson, D.E., Lurigio, A.J., \& Alderden, M. (2003). Men are from Mars, women are 
from Venus, but what role does gender play in probation recidivism. Justice Research and Policy, 5(2), 33-54.

Opsal, T. (2009). Women on parole: Understanding the impact of surveillance. Women \& Justice, 19(4), 306-328.

Opsal, T. (2012). Livin' on the straights': Identity, desistance, and work among women post-incarceration. Sociological Inquiry, 82(3), 378-403.

Opsal, T. (2015). “It's their world, so you've got to get through: Women's experiences of parole governance. Feminist criminology, 10(2), 188-207.

Owen, B., \& Bloom, B. (1995). Profiling women prisoners, Findings from national surveys and a California sample. The Prison Journal, 75, 165-185.

Petersilia, J. (1997). Probation in the United States. Crime an Justice: A Review of Research. 22, 30-41

Pew Center on the States. (2011). State of recidivism: The revolving door of America's Prisons. Washington, DC: Pew Center on the States.

Phelps, M.S. (2013). The paradox of probation: Community supervision in the age of mass incarceration. Law \& Policy. 35(1-2), 51-80.

Portes, A. (1998). Social capital: Its origins and applications in modern sociology. Annual Review of Sociology, 24, 1-24.

Reinharz, S. (1992). Feminist Methods in Social Research. New York, NY: Oxford University Press.

Reisig, M., Holtfreter, K., \& Morash, M. (2002). Social capital among women offenders. Journal of Contemporary Criminal Justice, 18(2), 169-182. 
Rembert, D., Henderson, H., \& Pirtle, D. (2014). Differential racial/ethnic predictive validity. Youth and Juvenile Justice, 12, 152-166.

Richie, B.E. (2001). Challenges incarcerated women face as they return to their communities: Findings from life history interviews. Crime \& Delinquency, 47(3), 368-389.

Rose, D.R., \& Clear, T.R. (1998). Incarceration, social capital, and crime: Implications for social disorganization theory. Criminology, 36, 441-479.

Salisbury, E.J., \& Van Voorhis, P. (2009). A quantitative investigation of women probationers' paths to incarceration. Criminal Justice and Behavior, 36(6), 541566.

Sawyer, W. (2016). The high cost of probation fees in Massachusetts. Northamptom, MA: The Prison Policy Institute.

Sentencing Project. (2015a). A lifetime of punishment: The impact of the felony drug ban on welfare benefits. Retrieved from http://www.sentencingproject.org/wpcontent/uploads/2015/12/A-Lifetime-of-Punishment.pdf.

Sentencing Project (2015b). Incarcerated women and girls. Retrieved from http://www.sentencingproject.org/wp-content/uploads/2016/02/IncarceratedWomen-and-Girls.pdf

Sentencing Project (2015c). Black lives matter: Eliminating racial inequity in the criminal justice system. Washington, D.C.

Shaffer, D.K., Hartman, J.L., Listwan, S.J. (2009). Drug abusing women in the community: The impact of drug court involvement on recidivism. The Journal of Drug Issues, 22, 803-828. 
Skeem, J., Louden, J.E., Polaschek, D., \& Camp, J. (2007). Assessing relationship quality in mandated community treatment blending care with control. Psychological Assessment, 19(4), 397-410.

Steadman, H.J., Redlich, A., Callahan, L., Robbins, P.C., \& Vesselinov, R. (2011). Effect of mental health courts on arrests and jail days: A multisite study. Arch Gen Psychiatry, 68(2), 167-172.

Steinmetz, K.F., \& Henderson, H. (2016). Inequality on probation: An examination of differential probation outcomes. Journal of Ethnicity in Criminal Justice, 14(1), $1-20$.

Steffensmeier, D. (1993). National trends in female arrests, 1960-1990: Assessment and recommendations for research. Journal of Quantitative Criminology, 9, 413-441.

Steffensmeier, D., \& Haynie, D. (2000). Gender, structural disadvantage, and urban crime: Do macrosocial variables also explain female offending rates? Criminology, 38(2), 403-438.

Straus, M., Hamby, S.L., Boney-McCoy, S., \& Sugarman, D.B. (1996). The revised conflict tactics scales (CTS2): Development and preliminary psychometric data. Journal of Family Issues, 17(3), 283-316.

Substance Abuse and Mental Health Services Administration. (2014). Trauma-informed care in behavioral health services. U.S. Department of Health and Human Services. Rockville, MD. 
Substance Abuse and Mental Health Services Administration for Behavioral Health Statistics and Quality. (2016) Results from the 2015 national survey on drug use and health: Detailed tables. Rockville, MD.

Swopes, R.M., Davis, J.L., \& Scholl. J.A. (2015). Treating substance abuse and trauma symptoms in incarcerated women: An effectiveness study. Journal of Interpersonal Violence, 1-23.

Tabachnick, B.G., \& Fidell, L.S. (2001). Using multivariate statistics $\left(4^{\text {th }}\right.$ ed.). Needham Heights, MA: Allyn and Bacone.

Tabachnick, B.G. \& Fidell, L.S. (2013). Using multivariate statistics, Boston, MA: Pearson.

Taxman, F.S., Perdoni, M.L., \& Harrison, L.D. (2007). Drug treatment services for adult offenders: The state of the state. Journal of Substance Abuse Treatment, 32(3), 239, 254.

Taylor, A. (2008). Substance use and abuse. Affilia, 23(2), 167-178.

Tonry, M., \& Lynch, M. (1996). Intermediate sanctions. Crime and Justice, 20, 99144.

Uggen, C., \& Thompson, M. (2003). The socioeconomic determinants of ill-gotten gains: Within-person changes in drug use and illegal earnings. American Journal of Sociology, 109(1), 146-185.

Vera Institute of Justice. (2016). Overlooked. Women and jails in the era of reform. Washington DC: Vera Institute of Justice. 
Volkow, N.D., Koob, G.F., \& McLellan, A.T. (2016). Neurobiologic advances from the brain disease model of addiction. The New England Journal of Medicine, 374(4), 363-371.

Watkins, K.E., Farmer, C.M., De Vries, D., Hepner, K.A. (2015). The affordable care act: An opportunity for improving care for substance use disorders? Psychiatric Services, 66(3), 310-312.

Wattanaporn, K.A., \& Holtfreter, K. (2014). The impact of feminist pathways research on gender-responsivity policy and practice. Feminist Criminology, 9(3), 191207.

Wells, K., Klap, R., Koike, A., \& Sherbourne, C. (2001). Ethnic disparities in unmet need for alcoholism, drug abuse, and mental health care. American Journal of Psychiatry, 158(12), 227-232.

Williams, M.L., Freeman, R.C., Bowen, A.M., Zhao, Z., Rusek, R. \& Signes (2002). A comparison of the reliability of self-reported drug use and sexual behaviors using computer-assisted versus face-to-face interviewing. AIDS Education and Prevention, 12, 199-213.

Wolff, N., Frueh, B.C., Shi, J., \& Schumann, B.E. (2012). Effectiveness of cognitivebehavioral trauma treatment for incarcerated women with mental illnesses and substance abuse disorders. Journal of Anxiety Disorders, 26, 703-710.

World Health Organization. (2014). Social determinants of mental health. Retrieved from http://apps.who.int/iris/bitstream/10665/112828/1/9789241506809 eng.pdf?ua $=1$ 
Yacus, G. (1998). Validation of the risk and needs assessment used in the classification for parole and probation of Virginia's adult criminal offenders. Dissertation Abstracts International. A, The Humanities and Social Sciences, $60,885$.

Zinn, H. (1980). A people's history of the United States. New York, NY: Harper and Row.

Zlotnick, C., Johnson, J., \& Najavits, L.M. (2009). Randomized controlled pilot study of cognitive-behavioral therapy in a sample of incarcerated women with substance use disorder and PTSD. Behavior Therapy, 40, 325-336.

Zlotnick, C., Najavits, L.M., Rohsenow, D.J., \& Johnson, D.M. (2003). A cognitivebehavioral treatment for incarcerated women with substance abuse disorder and posttraumatic stress disorder: Findings from a pilot study. Journal of Substance Abuse Treatment, 25, 99-105. 


\section{Appendix A}

Table A1.

Bivariate Racial Differences Between Income and Education

\begin{tabular}{|c|c|c|c|c|}
\hline Indicator & $\begin{array}{c}\text { African } \\
\text { American } \\
\text { (Percentage) }\end{array}$ & $\begin{array}{c}\text { White } \\
\text { (Percentage) }\end{array}$ & $\begin{array}{c}\text { “Other" } \\
\text { Category } \\
\text { (Percentage) }\end{array}$ & $\begin{array}{l}\text { Chi- } \\
\text { Square }\end{array}$ \\
\hline Income & & & & 3.876 \\
\hline Less than $\$ 500$ & 53.4 & 53.7 & 47.4 & \\
\hline$\$ 500-\$ 999$ & 35.3 & 31.5 & 31.6 & \\
\hline$\$ 1,000-\$ 1,999$ & 10.3 & 13.9 & 15.8 & \\
\hline$\$ 2,000-\$ 3,999$ & 0.4 & 0.9 & 5.3 & \\
\hline $\begin{array}{l}\text { Education Level } \\
\text { Less than High } \\
\text { School }\end{array}$ & 24.6 & 28.4 & 10.5 & 19.084 \\
\hline High School & 34.7 & 35.8 & 36.8 & \\
\hline $\begin{array}{l}\text { Some College/ } \\
\text { College }\end{array}$ & 32.2 & 33.0 & 31.6 & \\
\hline $\begin{array}{l}\text { Some Graduate/ } \\
\text { Graduate } \\
\text { School }\end{array}$ & 5.1 & 0.9 & 10.5 & \\
\hline
\end{tabular}




\title{
CURRICULUM VITA
}

\author{
Jordan Wilfong \\ Assistant Professor, Bowling Green State University \\ College of Health and Human Services \\ Department of Social Work \\ jwilfon@bgsu.edu \\ 412-657-4371
}

\section{Education}

PhD, Social Work, University of Louisville 2018

$\begin{array}{ll}\text { MSW, Widener University } & 2011\end{array}$

BS, Anthropology, James Madison University 2008

Academic Appointments

Assistant Professor of Social Work

2018-present

Bowling Green State University

College of Health \& Human Services

Department of Social Work

\section{$\underline{\text { Research Interests }}$}

- Criminology

- Restorative justice and therapeutic jurisprudence

- The interface of social work and the criminal justice system

- Child welfare families and foster care

- Social work education

\section{Peer-Reviewed Journal Articles}

Sears, J.S., Verbist, A.N., Wilfong, J., Thomas, T.A., Mount, S., Sabree, R., \& Van Zyl, M.A. (2018). Mapping the science of social work debate: An exercise in doctoral student education. The Journal of Social Work Education. 
Harris, L.M., Wilfong, J., Thang, N.D., \& Kim, B.J. (2017). Guardianship planning among grandparents raising grandchildren affected by HIV/AIDS in Northern Vietnam. GrandFamilies: The Contemporary Journal of Research, Practice and Policy, 4(1).

Hall, M.T., Wilfong, J., Huebner, R.A., Posze, L., \& Willauer, T. (2016). Medicationassisted treatment improves child permanency outcomes for opioid-using families in the child welfare system. Journal of Substance Abuse Treatment, 71, 63-67.

Journal Articles in Development

Wilfong, J. Assessing the influence of treatment access, gender, race, and income on the recidivism outcomes of women on probation.

Wilfong, J. Teaching social justice to online social work students: An exercise in macro social welfare policies.

Wilfong, J. A meta-synthesis of qualitative research studies including samples of women on probation or parole.

\section{Conference Presentations}

Wilfong, J. (2017). Qualitative studies including samples of women on probation or parole: A review of the literature and recommendations for future research and policy. Paper presented at the American Society of Criminology Annual Meeting. Philadelphia, PA. *Also served as session chair.

Harris, L.M., Wilfong, J., \& Schmidt, V. (2017). Effects of empathy clubs on health care among HIV-affected grandparent headed households in Vietnam. Poster presented at the IAGG World Congress of Gerontology and Geriatrics. San Francisco, CA.

Hall, M.T., Wilfong, J., Huebner, R.A., \& Willauer, T. (2017). Medication-assisted treatment improves child permanency outcomes for opioid-using families in the child welfare system. Paper presented at the Society for Social Work Research Annual Conference. New Orleans, LA.

Wilfong, J., Velez, A., Thomas, T., \& Golder, S. (2016). Interventions provided to women involved in the criminal justice system: A systematic review of the literature over the past 25 years. Paper presented at the American Society of Criminology Annual Meeting. New Orleans, LA.

Van Zyl, M.A., Verbist, A.N., Sears, J.S., Thomas, T.A., Wilfong, J., Mount, S., \& Sabree, R. (2016). The science of social work debate. Poster presented at the Society for Social Work Research Annual Conference. Washington, DC.

Harris, L.M., Wilfong, J., Thang, N.D., \& Kim, B.J. (2015). Temporary roles: Future 
care planning among grandparents raising grandchildren affected by HIV/AIDS in Vietnam. Poster presented at the Gerontological Society of America Annual Meeting. Orlando, FL.

Sears, J.S., \& Wilfong, J. (2015). Including the natural environment in social work education. A roundtable discussion facilitated at the Kentucky Association of Social Work Educators Conference. Frankfort, KY.

\section{Technical Papers and Reports}

Collins-Camargo, C., Wilfong, J., Collins, J. (2017). Child welfare caseload and workload: A synthesis of the evidence base, current trends, and future directions. Submitted to the Child Welfare League of America in collaboration with the Anne E. Casey Foundation and the William T. Grant Foundation.

\section{Teaching Experience}

Bowling Green State University:

Social Welfare Policy

- Fall 2018

Advanced Generalist Practice with Larger Systems

- $\quad$ Spring 2018

University of Louisville:

Advanced Macro Social Work Practice: MSSW Program

- Summer 2016-17 (both online and in-person)

- Fall 2016-17 (online)

Advanced Macro Social Work Integrative Practice: MSSW Program

- $\quad$ Spring 2017-18 (online)

Social Work Practicum I: BSW Program

- Fall 2015-17

Social Work Practicum II: BSW Program

- Spring 2016-18

\section{Awards and Honors}

University of Louisville Delphi Center for Teaching and Learning:

Faculty Favorite Nominee

\section{Clinical and Other Work Experience}

Outpatient Therapist, Positive Pathways

-Provided individual and family therapy with clients including children, families, adults, and couples.

-Focused on working with clients on mental health and substance 
misuse issues using various therapeutic modalities such as cognitive behavioral therapy, structural family therapy, and motivational interviewing.

Family Behavioral Resources, In-Home Therapist

-Provided individual and family therapy to children and adults.

-Focused on trauma-related cases using therapeutic techniques such as trauma-focused cognitive behavioral therapy.

-Collaborated regularly with the child welfare system, foster parents, the public school system, adoption lawyers, and county psychologists.

Social Work Intern, School District of Philadelphia

-Provided therapy at an inner-city middle school in Philadelphia with a focus on individual and group therapy.

-Collaborated with guidance counselors, teachers, and school polices on behavioral goals for students.

Social Work Intern, Social Work Counseling Services

$2009-10$

-Provided individual mental health counseling for adults and co-ran a therapeutic and job development program for recent high school graduates.

-Collaborated with community leaders on recruitment of participants and connecting clients to employment opportunities

Substitute Teacher, Career Connections Charter School

-Regular substitute teaching role at a high school.

Research Experience

Researcher, Child Welfare League of America

$2017-18$

A national study on child welfare caseload and workload standards

Funded by Anne E. Casey Foundation with support from the William

T. Grant Foundation

Graduate Research Assistant, University of Louisville

The Center for Promoting Recovery and Resilience of Traumatized

Children and Youth

Principle Investigator: Bibhuti Sar, Ph.D.

\section{Funding}

University of Louisville Social Work Travel Grant: \$800 2017

Ruth Huber Scholarship for Presentations and Publications: \$200 2017

University of Louisville Graduate Student Travel: \$350 2016

University of Louisville Social Work Travel Grant: \$800 2015

Grant Applications Completed

National Institute of Drug Abuse Dissertation Grant (R36) (unfunded) 2017 
Service

BGSU Working Group, Crime and Violence in Context (member)

2018-present

Kent School of Social Work, Strategic Planning Committee on

Educational Excellence

$2017-18$

Kent School of Social Work, Social Justice Committee, Subgroup on

Poverty and Community Policing

$2017-18$

Judge-BSW Senior Capstone Presentations

2015-18

Guest Speaker-Survivors of Torture Board Meeting

2015

Participant-Roundtable Discussion on U.S. Social Work with German

Exchange Students.

2015

Co-Facilitator-Trauma Therapy Group for Somali Teens

$2014-15$

Continuing Education

Canvas 101 Online Teaching Workshop 2018

Kent School of Social Work, Teaching Academy Certificate 2016

DELPHI Education Center, Online Education Training Certificate 2017

\section{Professional Licenses}

Masters Level Certified Social Worker (CSW) in Kentucky

Masters Level Licensed Social Worker (LSW) in Pennsylvania (currently inactive)

Professional Affiliations

American Society of Criminology

2016-present

Council for Social Work Education

2017-present

National Association of Social Workers

2011-15

Society for Society Work and Research

2014-2018

Community Service

West Penn Hospital STAR Center-Program Consultant

2012-present

St. Joseph's Church Soup Kitchen-Volunteer

$2007-10$

The ARC of Harrisonburg and Rockingham Co.-Volunteer

2005-06

Springdale, PA Yearly Free Flu Vaccine Event-Volunteer

2000-04

\section{Study Abroad}

London, England 